\title{
DEGREE PROJECT
}

\section{Tribological Performance of Hygrothermally Aged UHMWPE Hybrid Composites}

Luca Palmeira Belotti

Mechanical Engineering, master's level (120 credits) 2018

Luleå University of Technology

Department of Engineering Sciences and Mathematics 



\section{Acknowledgments}

This project was carried out at the Biotribology and Polymer Composites group in the Division of Machine Elements at Luleå University of Technology (LTU) as part of the TRIBOS program - Joint European Master in Tribology of Surfaces and Interfaces. I would like to thank everyone involved in the organization of the TRIBOS for making this opportunity possible by funding, guiding and supporting throughout this 2-year journey.

Thanks to Professor Nazanin Emami and Hari Shankar for the guidance, support, discussions, and patience throughout the work. Also, I would like to thank all the TRIBOS colleagues and TRIBOLAB staff for the help and friendship. Finally, I am grateful to LTU for hosting and providing resources for this research and education opportunity. 


\begin{abstract}
Stricter environmental regulations and trend of decreasing cost and increasing operational efficiency are the driving forces for the improvement of the tribological performance in many different industries. For example, in the case of hydropower plants, there has been increasing research carried out to achieve oil-free stations, which would substitute the oil-based lubricants with environmentally accepted lubricants or water. In this application, water could be a good alternative due to its availability and low cost. Also, water is non-toxic and has high heat capacity. Although advantageous, using water as a lubricant presents many challenges that limit its application such as corrosiveness and thin lubricant film due to its physical properties. Therefore, the material selection for the interacting surfaces needs to be correctly performed when considering water-lubricated conditions because of the harsher tribological conditions to which they will be susceptible.

Polymeric materials, such as Ultra High Molecular Weight Polyethylene (UHMWPE), are good candidates for such water-lubricated applications due to versatile mechanical and thermal properties, as well as good tribological characteristics. Today, these materials find use in different tribological components, such as bearings, liners, and gears. However, high wear rates limit their applications, due to the reduced operating life. The performance can be improved in different ways, including surface modification, polymer blending, and the use of reinforcements. A novel research area is hybrid and multiscale reinforced composites, which combines the use of micro and nanofillers to obtain improved performances.

UHMWPE has been thoroughly studied, including mechanical, thermal and tribological behavior. However, there are limited studies on the effects of hygrothermal aging on the friction and wear response of UHMWPE. The studies are even more restricted when considering reinforced materials. Therefore, this work aims to investigate the effect of hygrothermal aging in the tribological performance of UHMWPE composites in waterlubricated conditions. Aging exposure and tribological tests were performed to evaluate the response of the materials, and the main conclusion of this work is that the tribological response of UHMWPE composites was not significantly affected by the test exposure conditions.
\end{abstract}




\section{Table of contents}

List of figures...........................................................................................................................

List of tables............................................................................................................

Abbreviations ..................................................................................................... vii

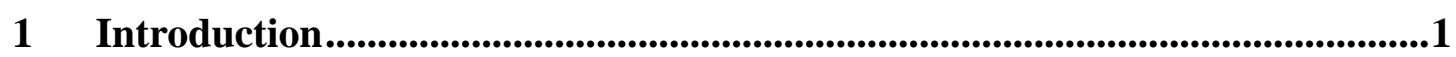

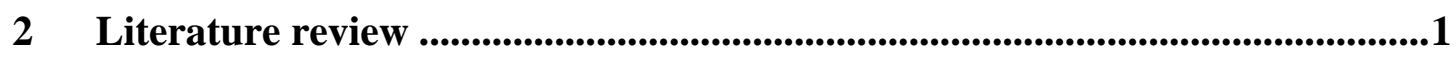

$2.1 \quad$ Water-lubricated contacts ..........................................................................

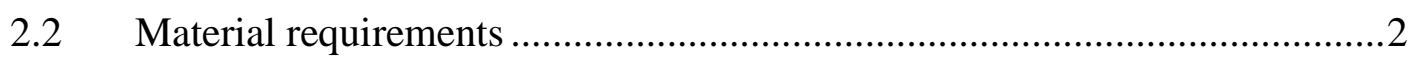

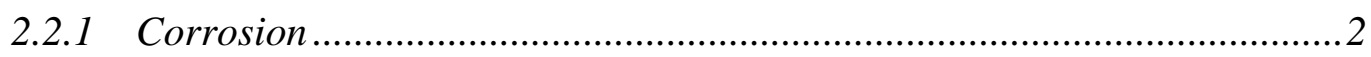

2.2.2 Thermal conductivity and thermal expansion ............................................

2.2.3 Water absorption ...............................................................................

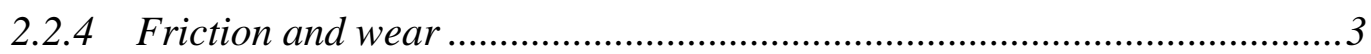

$2.3 \quad$ Polymer-based materials ......................................................................

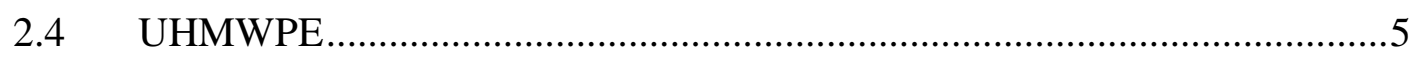

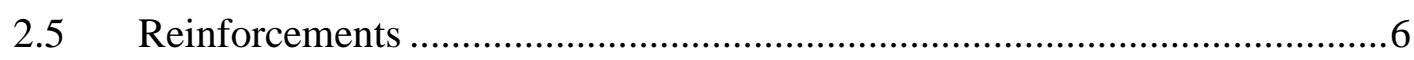

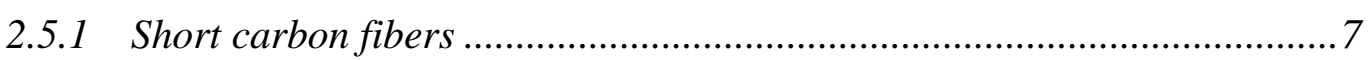

2.5.2 Graphene Oxide ...........................................................................

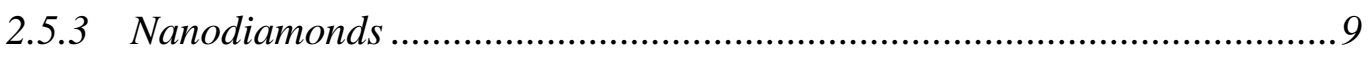

3 Research gap............................................................................................................11

4 Purpose of the study...........................................................................................11

5 Experimental work .......................................................................................................11

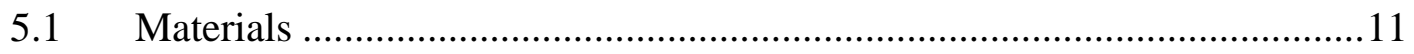

5.1.1 Polymer composites ……………………………............................

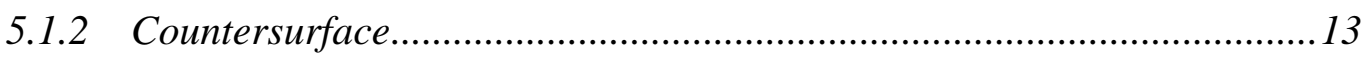

5.1.3 Sample preparation......................................................................... 13

$5.2 \quad$ Hygrothermal aging ............................................................................... 14

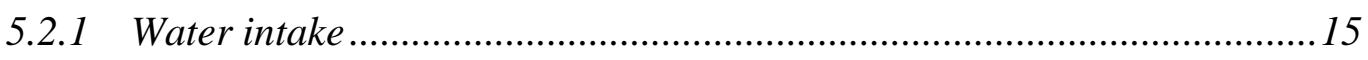

5.2.2 Wettability and surface energy ........................................................... 16

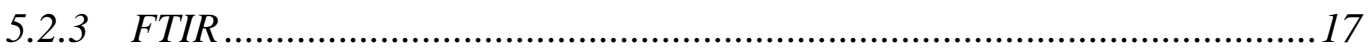

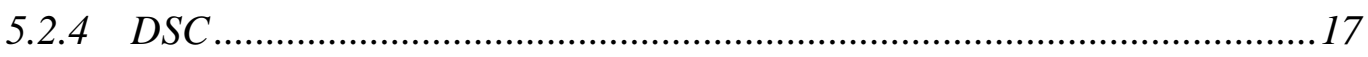

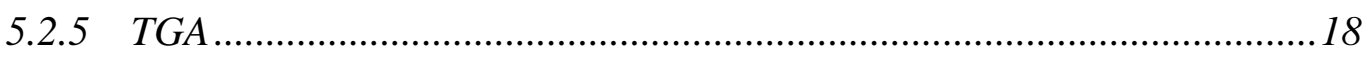

$5.3 \quad$ Tribological evaluation ......................................................................

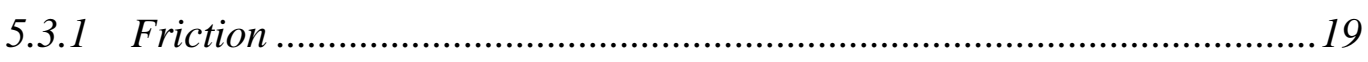

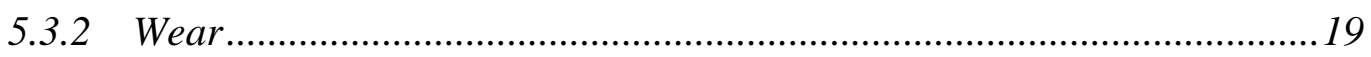




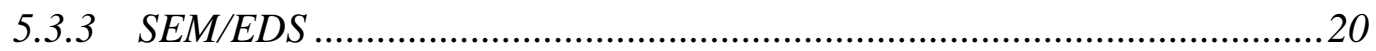

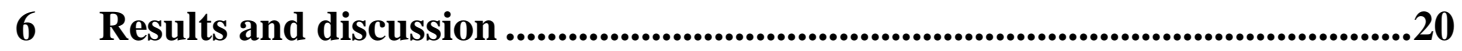

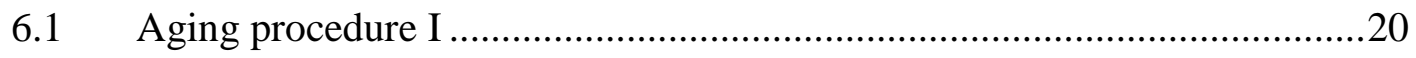

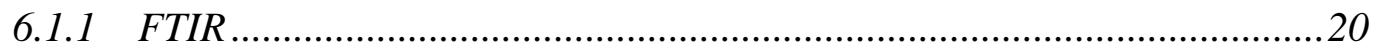

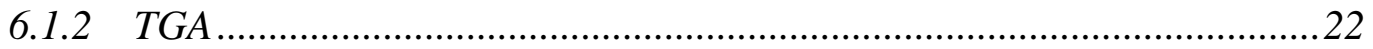

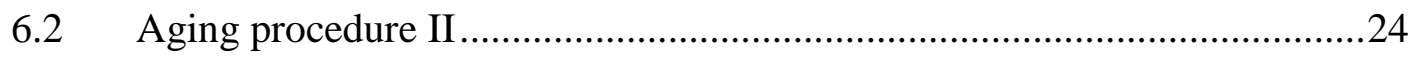

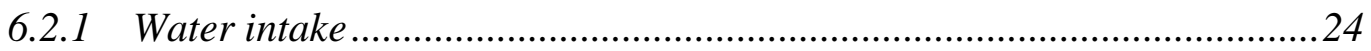

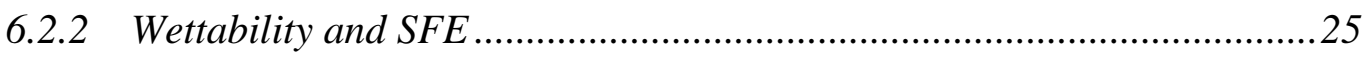

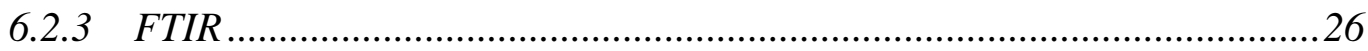

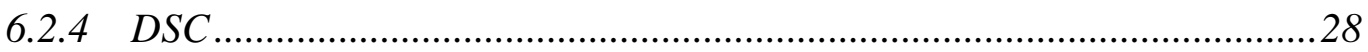

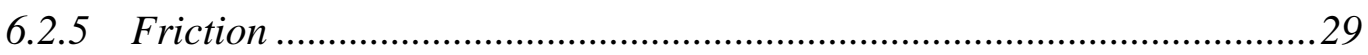

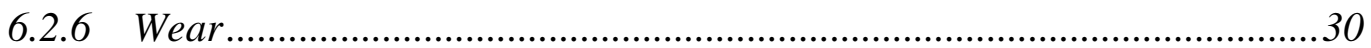

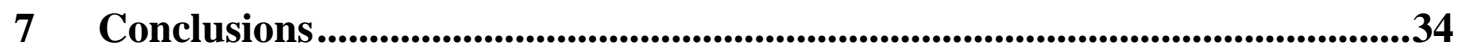

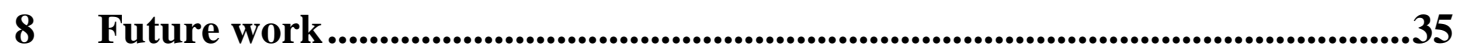

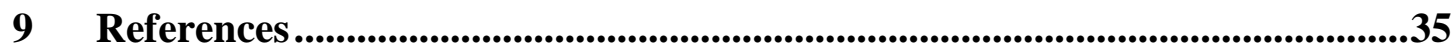




\section{List of figures}

Figure 2.4.1 Ethylene monomer.

Figure 2.4.2 Volume loss versus sliding distance under dry and water lubricated conditions [25].

Figure 2.5.1 Crystal structure of graphite [38] ..................................................

Figure 2.5.2 Chemical structure of GO based on the Lerf-Klinowski model with epoxy and hydroxyl groups functionalizing the surface [46].

Figure 2.5.3 Detonation scheme for ND synthesis [49].

Figure 2.5.4 (Left) Schematic of a near-spherical diamond particle. (Right) Typical ND particle synthesized by detonation [52].

Figure 5.1.1 (Left) Sample for thermal characterization. (Right) Aging sample for tribological testing. Dimensions shown are presented in millimeters. ..........................14

Figure 5.3.1 Schematic of the pin-on-disc configuration. .......................................18

Figure 5.3.2 Wear behavior of a component. I. running-in; II. steady state wear; III.

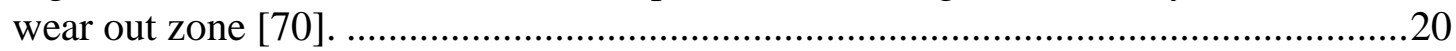

Figure 6.1.1 ATR-FTIR spectra for unfilled UHMWPE.......................................21

Figure 6.1.2 ATR-FTIR spectra for hybrid UHMWPE composites..........................21

Figure 6.1.3 ATR-FTIR for UHMWPE reinforced with micro and nano-sized fillers.

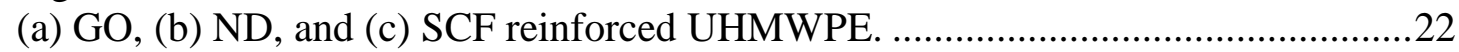

Figure 6.1.4 Decomposition curves for unaged materials. ......................................23

Figure 6.2.1 Water intake for composite materials with long-term exposure to water

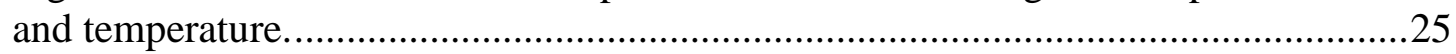

Figure 6.2.2 Water contact angle of the composites with aging time and temperature.

Figure 6.2.3 ATR-FTIR spectra of UHMWPE.

Figure 6.2.4 ATR-FTIR for UHMWPE reinforced with micro and nano-sized fillers.

(a) GO, (b) ND, (c) SCF, and (d) hybrid reinforced UHMWPE.............................28

Figure 6.2.5 The coefficient of friction of the composites sliding against Inconel 625

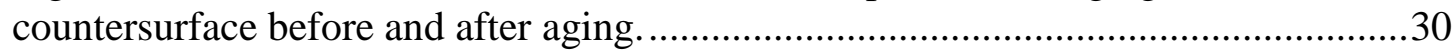

Figure 6.2.6 The relationship between the coefficient of friction and contact angle...30

Figure 6.2.7 Specific wear rate of the composites sliding against Inconel 625

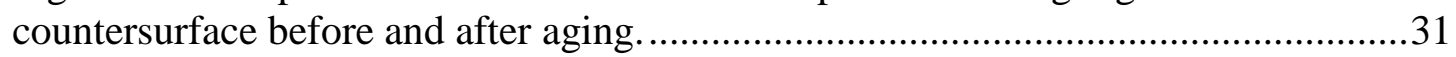

Figure 6.2.8 The relationship between SWR and coefficient of friction. ....................31

Figure 6.2.9 The relationship between SWR and contact angle.................................32

Figure 6.2.10 Worn pin surface of unfilled UHMWPE for different test aging conditions. (Left) Magnification 65x. (Right) Magnification 1000x and sliding

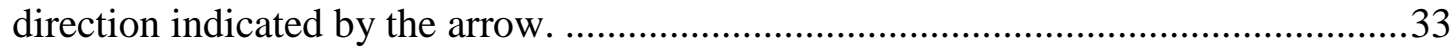

Figure 6.2.11(Left) SCF reinforced UHMWPE unaged worn pin surface. (Right) GO

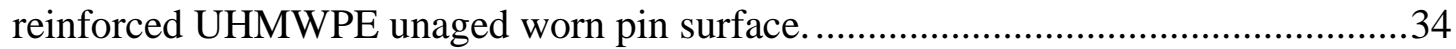

Figure 6.2.12 Wear track of hybrid UHMWPE/metal contact. ..................................34 


\section{List of tables}

Table 2.1.1 Properties of common liquid lubricants at atmospheric pressure (adapted

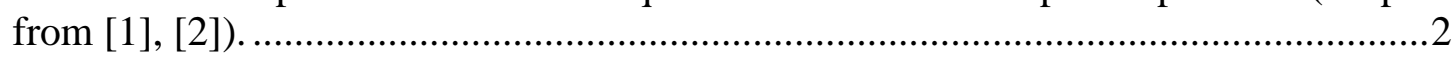

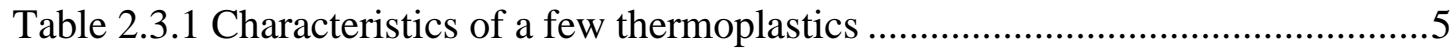

Table 2.3.2 Physical and mechanical properties of a few thermoplastics .....................5

Table 2.5.1 Summary of effect of fillers used as polymer matrix reinforcements ........7

Table 5.1.1 Physical properties of MIPELON ${ }^{T M}$ UHMWPE XM-220 ......................12

Table 5.1.2 Physical properties of Tenax ${ }^{\circledR}$-A HT M100 100mu................................12

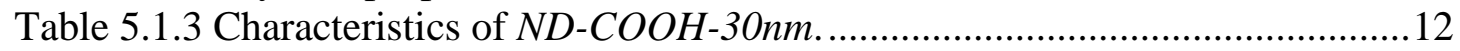

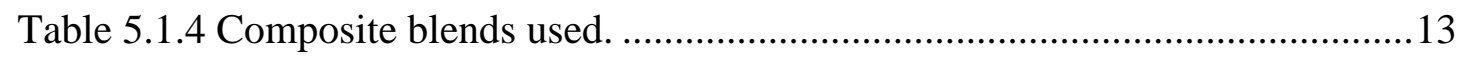

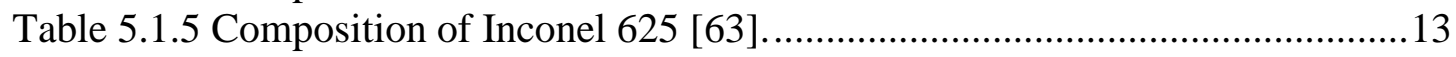

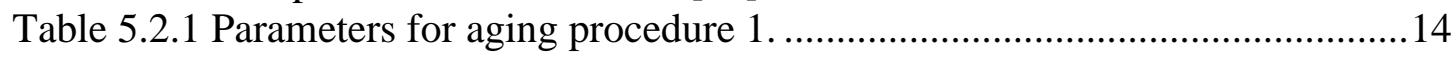

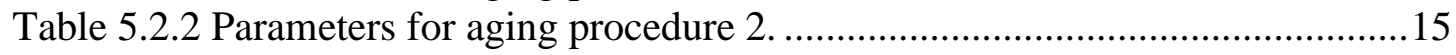

Table 5.2.3 Analyses used for each aging procedure............................................... 15

Table 5.2.4 Parameters used for the sessile experiment. .............................................16

Table 5.2.5 Surface tension information of water and diiodomethane......................17

Table 5.3.1 Pin-on-disc test conditions........................................................................ 19

Table 6.1.1 Decomposition temperatures obtained from TGA analysis for UHMWPE

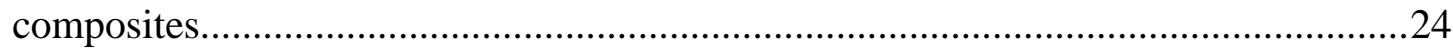

Table 6.2.1 SFE of the composites before aging calculated using OWRK method...26

Table 6.2.2 Calculated degree of crystallinity of composites..................................29 


\section{Abbreviations}

$\begin{array}{ll}\alpha & \text { Pressure-viscosity coefficient } \\ A T R & \text { Attenuated total reflectance } \\ B E I & \text { Backscattered electron } \\ C N T & \text { Carbon nanotubes } \\ \Delta M \% & \text { Mass variation } \\ D S C & \text { Differential scanning calorimetry } \\ E D S & \text { Energy-dispersive X-ray spectroscopy } \\ \eta & \text { Dynamic viscosity } \\ E & \text { Elastic modulus } \\ F f & \text { Friction force } \\ F T I R & \text { Fourier transform infrared spectroscopy } \\ g & \text { Acceleration of gravity at sea level }\left(9.80665 \text { m.s }{ }^{-2}\right) \\ G F & \text { Glass fiber } \\ G O & \text { Graphene oxide } \\ H & \text { Hardness } \\ H_{f} & \text { Enthalpy of fusion } \\ L C C & \text { Load carrying capacity } \\ L V D T & \text { Linear variable differential transformer } \\ M_{o} & \text { Mass of the dry sample } \\ M_{t} & \text { Mass of the aged sample at step “t." } \\ N D & \text { Nanodiamonds } \\ v & \text { Kinematic viscosity } \\ P & \text { Normal load } \\ P B M & \text { Polymer-based material } \\ P O D & \text { Pin-on-disc } \\ \rho & \text { Density } \\ S C F & \text { Short carbon fiber } \\ S E I & \text { Secondary electron } \\ S E M & \text { Scanning electron microscope } \\ S F E & \text { Surface energy } \\ S W R & \text { Specific wear rate } \\ \sigma & \text { Flexural strength } \\ T G A & \text { Thermogravimetric analysis } \\ & \end{array}$




$\begin{array}{ll}T_{g} & \text { Glass temperature } \\ T_{m} & \text { Melting temperature } \\ U H M W P E & \text { Ultra-High-Molecular-Weight-Polyethylene } \\ U T S & \text { Ultimate tensile strength } \\ W_{f} & \text { Weight fraction of fillers } \\ w t \% & \text { Weight percentage } \\ X_{c} & \text { Degree of crystallinity } \\ V I & \text { Viscosity index }\end{array}$




\section{Introduction}

There is a general trend and need in global industries to reduce negative tribological effects such as wear and friction within moving mechanical components. The goal is to reduce the costs and increase the operation efficiency of machines and mechanical components. Components, such as bearing linings, bushes, and prosthetics, should have longer lifespans, be lighter, be easy to manufacture and be cost-efficient. Furthermore, the environmental regulations are becoming stricter every year, and an economically viable environmentally acceptable operation is a necessity.

Conforming to the industrial demands is challenging and has been the object of substantial investment. Substituting the usage of oil-based lubricants with environmentally adaptive lubricants (EAL) or water is one direction. Another would be the replacement of metallic components by polymer-based materials (PBMs).

The use of water as a lubricant has been considered for a long time. Water offers benefits compared to other lubricants, including non-toxicity, availability and high heat capacity. However, it exhibits some significant drawbacks that limit its tribological application, such as low viscosity, pressure-viscosity coefficient, and corrosiveness. The lower viscosity and pressure-viscosity coefficients are essential when considering lubricated contacts because they affect the formation and load carrying capacity of the lubricant film. Usually, water-lubricated contacts operate under boundary lubricating conditions. Therefore, when designing a system for such operation, it is necessary to consider the operating conditions, environment, and materials carefully.

PBMs are candidates for water-lubricated contacts because they exhibit excellent corrosion resistance, tailorable structure, and self-lubricating mechanisms, making them attractive for tribological applications. The easily modifiable structure allows versatile tailoring of mechanical and thermal properties, as well as tribological performance. Although versatile, PBMs are susceptible to water absorption, high abrasive wear rates, and viscoelastic deformation, which limit their application. However, these limitations can be overcome in different ways, such as polymer blending, the addition of reinforcements, surface modification and crosslinking. PBMs applied in tribological components in the industry are mostly reinforced, which means that they incorporate fillers to provide or improve specific properties that are beneficial for a particular component.

\section{Literature review}

\subsection{Water-lubricated contacts}

Lubricated contact is found when a lubricant is applied to reduce friction, wear and provide smooth operation where there is relative motion between two bodies. Solids, liquids, and gases can be used as lubricants depending on the application and its requirements. The most widely applied lubricants are liquid, some examples being mineral oils, synthetic esters, and water.

The reduction of friction and wear results from the formation of lubricant film that separates or prevent high shear rates between two sliding objects [1]. Also, it reduces the damage on the surfaces by bearing part of the load present in the contact between the two bodies in motion. The thickness and bearing capacity of the film depends on 
the operation conditions (load, temperature, relative velocity), properties of the lubricant (viscosity and pressure-viscosity coefficient) and the surface topography of the two bodies being lubricated. Table 2.1.1 shows some examples of liquid lubricants.

Table 2.1.1 Properties of common liquid lubricants at atmospheric pressure (adapted from [1], [2]).

\begin{tabular}{lcccccc}
\hline \multirow{2}{*}{ Lubricants } & \multicolumn{3}{c}{$\boldsymbol{\eta}\left[\mathbf{x 1 0 ^ { - 3 }}\right.$ Pas $]$} & \multicolumn{3}{c}{$\boldsymbol{\alpha}\left[\times \mathbf{x 1 0}^{-9} \mathbf{P a}^{-1}\right]$} \\
& $\mathbf{3 0}^{\circ} \mathbf{C}$ & $\mathbf{6 0}^{\mathbf{0}} \mathbf{C}$ & $\mathbf{1 0 0}^{\mathbf{}} \mathbf{C}$ & $\mathbf{3 0}^{\circ} \mathbf{C}$ & $\mathbf{6 0}^{\circ} \mathbf{C}$ & $\mathbf{1 0 0}^{\circ} \mathbf{C}$ \\
\hline High VI - light machine oil & 38 & 12.1 & 5.3 & - & 18.4 & 13.4 \\
High VI - heavy machine oil & 250 & 50.5 & 12.6 & 25.0 & 21.3 & 17.6 \\
Medium VI - spindle oil & 18.6 & 6.3 & 2.4 & 20 & 16 & 13 \\
Low VI - heavy machine oil & 310 & 44.2 & 9.4 & 34.6 & 26.3 & 19.5 \\
Water & 0.80 & 0.47 & 0.28 & 0 & 0 & 0 \\
\hline
\end{tabular}

As seen in table 2.1.1, the dynamic viscosity and pressure-viscosity coefficients of water are considerably lower than other liquid lubricants, meaning that the lubricant film formed by water is thinner and has lower LCC if compared to other lubricants, such as oil-based lubricants. Thus, two surfaces in relative motion lubricated by water may be in contact due to the resultant thinner film. Also, water is a corrosive medium, which contributes to the physical and chemical deterioration of materials.

The combination of the physical properties and corrosive nature of water are major challenges to be overcome when considering it as a lubricant. Despite the challenges, there are benefits of using it, such as availability, non-toxicity and high-heat capacity.

\subsection{Material requirements}

Water-lubricated contacts are present in various industries, including food, marine and hydropower industries [3]. Due to the thinner lubricant film, contact between two surfaces in relative motion is expected (boundary lubrication). Therefore, it is critical to select the materials of the surfaces correctly, so that the chosen system will be able to efficiently and reliably operate longer. The criteria for material selection involves a combination of mechanical, structural and thermal properties, tribological performance, and ease of manufacturing combined with the operation requirements [4]. In the following sections, some critical material selection considerations are discussed.

\subsubsection{Corrosion}

Corrosion can have a beneficial or detrimental effect on tribological contacts. The benefits range from the formation of surface layers that prevents internal material corrosion to low shearing resistance layers. However, when detrimental, it can negatively affect the mechanical properties, structural integrity and tribological performance of a component, thus reducing its service life.

Corrosion is dependent on the environment and operation conditions and might occur via different mechanisms, such as galvanic corrosion, crevice corrosion, and pitting. Water is a corrosive medium where the risk of corrosion is more critical for conductive materials because water acts as an electrolyte for the corrosive reactions [5]. Therefore, the choice of a pair of conductive-nonconductive materials is vital for the waterlubricated applications [1]. 
It has been shown that debris and wear particles resulting from corrosion mechanisms for metallic surfaces are hard enough to scratch polymer surfaces when detached [6], [7]. Wang et al. studied the sliding behavior of UHMWPE against GCr15 and Ni-CrWC on pure water and seawater lubricated conditions. Their results suggested higher friction coefficients and specific wear rates when sliding against GCr15 in seawater than pure water. Also, for Ni-Cr-WC when sliding in seawater the friction coefficient and specific wear rates are lower than in pure water. This behavior was explained by the corrosion of the countersurface, which affects the debris generation and the wear mechanism of the polymeric material [8].

\subsubsection{Thermal conductivity and thermal expansion}

Whenever there is contact between two surfaces in relative motion, energy will be dissipated due to frictional heat. Therefore, the usage of materials with higher thermal conductivity is desired as the rise in the asperity temperature is less significant than materials with lower conductivity.

As already mentioned, an attractive property of water is its high heat capacity, which allows efficient heat dissipation. Therefore, when considering water as a lubricant, the choice of materials with lower thermal conductivity is possible since part of the frictional heat dissipates in water [3].

However, the thermal conductivity of a material is not enough for the selection of the material. The thermal expansion should be considered as well because it expresses the tendency of change in shape and geometry when variation in temperature is present. In the case of bearings, if the material considerably expands, it may come into contact with the shaft and act as a break instead of a bearing [3], [9]. Thus, bearing materials should be selected in a way that the thermal expansion of it would be within the tolerances of the project and has proper thermal conductivity.

\subsubsection{Water absorption}

Water influences the material properties and tribological behavior, and thus its performance under sliding contact. The interaction between surface and water are diverse, and time, temperature, load, velocity, surface topography dependent. Some examples of interaction are absorption, adsorption and chemical reactions [4], [10].

Water absorption may result in component geometry change due to swelling. Similarly to the thermal expansion explanation, if the swelling surpasses the tolerances in a bearing, it could act as a break instead of bearing [11], [12], losing its purpose. Therefore, the selected material for water applications should exhibit low water solubility and water absorption rate.

Mohebby et al. investigated the effect of water and moisture absorption behavior in Polypropylene/Wood Flour/Glass fiber hybrid composites. Their results showed that increasing the concentration of glass fiber resulted in higher water absorption and swelling (both measured in percentage) if no coupling agent was used [13]. Similarly, Zifeng and Guomei studied the effect of irradiation on the water intake of UHMWPE materials. Their results suggested low weight variation of the irradiated UHMWPE samples [14], suggesting that UHMWPE is a suitable material for water environments.

\subsubsection{Friction and wear}

Friction and wear are two tribological responses that critically affect the performance and lifespan of bearings. Friction is defined as the resistance to the relative sliding 
between two surfaces and is one of the primary sources of energy dissipation due to heat. Wear is the mechanism of material removal from one surface due to interaction with another.

If, for example, when starting a system the friction and adhesion between two surfaces are high, significant damage may happen [9], which may lead to premature failure of the component. Adhesion is known to have a considerable impact on both friction and wear of materials. Rabinowicz concluded that the more soluble are two materials, the stronger is the adhesion between them, increasing friction [15]. However, if this initial high friction and wear are controlled, it can be beneficial. This initial stage is known as running-in, which is when the system is operating until it reaches its steady state for friction and wear by smoothening the surfaces and reducing the contact pressure.

Several researchers have shown the benefits of running-in for extended tribological operations. Lancaster used $\mathrm{Al}_{2} \mathrm{O}_{3}$ abrasives on water lubricated lignum vitae bearings [10]. He observed a reduction of the combined surface roughness of the two mating surfaces due to abrasives, which reduced the total wear rate and friction of the system. Jalali et al. showed similar running-in benefits when studying UHMWPE hip joint replacements [16].

\subsection{Polymer-based materials}

PBMs are worthy candidates for water-lubricated tribological applications. They exhibit many favorable characteristics for tribological applications, such as high toughness and damage tolerance, good thermal stability, corrosion resistance and selflubricating mechanisms [17]. Polymers used in tribological applications are classified as thermoset or thermoplastic.

Thermosets are polymers that change irreversibly from the solid-liquid state when reaching the curing temperature. They have been applied for medium to heavy load tribological applications such as bearing and bush material in marine applications and worm wheels [18]. Some examples of thermoset plastics are epoxy resin, melamine formaldehyde, and polyester resin [19]. However, thermosets show some drawbacks, such as limited shelf life, low toughness, low strain to failure, moisture sensitivity and toxicity [17].

Thermoplastics, differently from thermosets, can reversibly change from solid to liquid state, recovering their mechanical properties with the phase transformation (recyclable). They can display semi-crystalline and amorphous structures, which affect their mechanical properties. Amorphous structures are disordered and responsible for the elastic characteristics. Semi-crystalline structures are compact and ordered, which provides mechanical and thermal properties for the material. Compared to thermosets, they exhibit advantageous characteristics, such as indeterminate shell life, low moisture absorption, thermal stability, high toughness and damage tolerance, and lower environmental impact [17]. However, thermoplastics exhibit lower shear, compression strengths and poor creep behavior, which limits their application.

Nevertheless, thermoplastics are found in various industries ranging from low to high loads, such as marine, biomedical and hydropower. Table 2.3.1 presents characteristics of some thermoplastics used for bearing applications. Table 2.3.2 presents some mechanical properties of the polymers introduced in Table 2.3.1. 
Table 2.3.1 Characteristics of a few thermoplastics

\begin{tabular}{|c|c|c|c|c|c|c|c|}
\hline Polymer & \multicolumn{3}{|c|}{ Name } & \multicolumn{4}{|c|}{ Characteristics } \\
\hline $\begin{array}{l}\text { UHMWPE [17], } \\
\text { [20] }\end{array}$ & \multicolumn{3}{|c|}{$\begin{array}{l}\text { Ultra-high-molecular- } \\
\text { weight polyethylene }\end{array}$} & \multicolumn{4}{|c|}{$\begin{array}{l}\text { Bio-compatibility, high wear resistance, low coefficient } \\
\text { of friction }\end{array}$} \\
\hline $\begin{array}{l}\text { PTFE [17], [21], } \\
\text { [22] }\end{array}$ & \multicolumn{3}{|c|}{ Polytetrafluoroethylene } & \multicolumn{4}{|c|}{$\begin{array}{l}\text { Low coefficient of friction, thermal stability, chemical } \\
\text { stability }\end{array}$} \\
\hline PEEK [18], [23] & \multicolumn{3}{|c|}{ Polyetheretherketone } & \multicolumn{4}{|c|}{$\begin{array}{l}\text { Excellent chemical resistance, toughness, good } \\
\text { mechanical strength, easy processability }\end{array}$} \\
\hline PAI [18] & \multicolumn{3}{|c|}{ Poliamideimide } & \multicolumn{4}{|c|}{$\begin{array}{l}\text { Good for extreme condition applications, excellent } \\
\text { thermal stability, mechanical strength and stiffness, and } \\
\text { chemical inertness, poor moisture resistance. }\end{array}$} \\
\hline PPS [18] & \multicolumn{3}{|c|}{ Poly(phenylene sulfide) } & \multicolumn{4}{|c|}{$\begin{array}{l}\text { Excellent mechanical strength, wear resistance and low } \\
\text { coefficient of friction, corrosion resistance, low } \\
\text { toughness. }\end{array}$} \\
\hline \multicolumn{8}{|c|}{ Table 2.3.2 Physical and mechanical properties of a few thermoplastics } \\
\hline Polymer & $\underset{\left[\mathrm{g} / \mathrm{cm}^{3}\right]}{\rho}$ & $\begin{array}{c}\mathbf{E} \\
{[\mathbf{G P a}]}\end{array}$ & $\begin{array}{c}\text { UTS } \\
{[\mathrm{MPa}]}\end{array}$ & $\stackrel{\stackrel{\sigma}{\mathrm{MPa}}]}{[-2}$ & $\begin{array}{c}\mathbf{H} \\
{[\mathrm{MPa}]}\end{array}$ & $\begin{array}{c}\mathbf{T}_{\mathbf{m}} \\
{\left[{ }^{\circ} \mathbf{C}\right]}\end{array}$ & $\underset{\left[{ }^{\circ} \mathbf{C}\right]}{\mathbf{T}_{\mathbf{g}}}$ \\
\hline $\begin{array}{l}\text { UHMWPE [17], } \\
{[20]}\end{array}$ & 0.93 & 0.8 & 23 & 40 & 65 & 135 & -160 \\
\hline PTFE [17], [20] & 2.15 & 0.4 & $25-36$ & $18-20$ & 30 & 300 & 127 \\
\hline PEEK [17], [20] & 1.3 & * & 70 & * & M99 & 334 & 145 \\
\hline PAI [18] & 1.42 & 4.5 & 152 & 241 & M120 & Serv. Temp.: 275 & 280 \\
\hline PPS [18] & 1.3 & 3.5 & 90 & 146 & $123 \mathrm{R}$ & 285 & 85 \\
\hline
\end{tabular}

\subsection{UHMWPE}

UHMWPE is a semi-crystalline thermoplastic formed by long chains (over 100,000 repetitions) of aligned ethylene monomers (Fig. 2.4.1), with a molecular weight larger than 3.5 million amu [22].

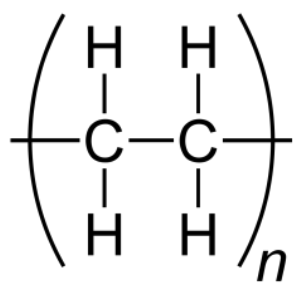

Figure 2.4.1 Ethylene monomer.

UHMWPE has been thoroughly studied and has broad application (i.e., biomedical implants, bearings and general manufacturing). The broad use is due to balanced mechanical, thermal and chemical properties, as well as corrosion resistance, low moisture absorption and excellent tribological behavior [23]. However, it displays high abrasive wear rates and susceptibility to viscoelastic deformation, which limit its tribological use. These limitations can be overcome by the use of different ways, such as the use of reinforcements, surface modification, and polymer blending.

Sukumaran et al. studied the tribological performance of several thermosets (PAI, PPSU, PEI, and PC) and thermoplastics (PET, UHMWPE, PA6, 1023PVDF and PPS) 
regarding dry heavy-duty applications. They concluded that UHMWPE, PA6, and PVDF experienced mild adhesive wear, and therefore were more suitable than other materials for heavy-duty wear applications. Also, their results showed that UHMWPE and PVDF performed the best in regards to friction, which could be explained by the persistent formation of transfer layer [24].

Marcus and Allen studied the sliding wear behavior of different grades of UHMWPE in an aqueous environment. They identified the reduction in wear of the samples when the contact was lubricated in water if compared to dry sliding (Fig 2.4.2). Also, they showed that the presence of water did not halt the formation of the transfer film. However, their main conclusion was that the wear performance is strongly dependent on the polymer structure, countersurface material and topography, environment and operating conditions, and reinforcements in the polymer composite [25].

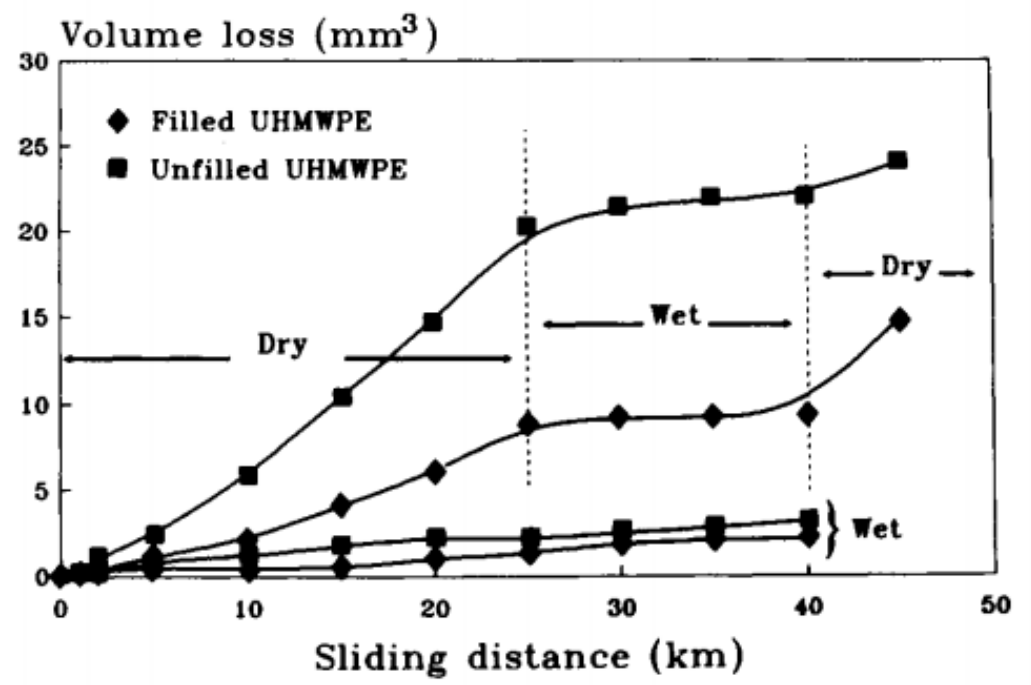

Figure 2.4.2 Volume loss versus sliding distance under dry and water lubricated conditions [25].

\subsection{Reinforcements}

As explained before, the use of fillers is one way to overcome the limitations of PBMs applications. They are used to tailor specific characteristics of the original polymer matrix such as UTS, friction and wear behavior. However, the use of fillers needs to be considered and designed with care as the improvement of one property may come with the compromise of other [26].

The reinforcements can be of many different natures, some being carbon-based (SCF, $\mathrm{GO}, \mathrm{ND}, \mathrm{CNT})$, ceramic $\left(\mathrm{TiO}_{2}, \mathrm{ZrO}_{2}, \mathrm{Al}_{2} \mathrm{O}_{3}\right)$ and metallic $(\mathrm{Zr}, \mathrm{Al})$. They also can be of different sizes, being macro and nano-sized materials the most common. Table 2.5.1 shows a summary of the effect of some previously studied materials used as polymer matrix reinforcements. 
Table 2.5.1 Summary of effect of fillers used as polymer matrix reinforcements

\section{Reinforcement Effect}

SCF [26] Improve wear resistance, improve strength, reduce toughness

ND [26] Increases strength and tribological performance

CNT [27] Improve wear resistance

$\mathrm{GO}[28] \quad$ Improve wear resistance, reduce fracture of composites

GF [27] Increase creep resistance, compressive strength, reduce toughness

$\mathrm{Al}_{2} \mathrm{O}_{3} / \mathrm{TiO}_{2}[26] \quad$ Improve wear resistance, thermal conductivity

PTFE / graphite Improve wear resistance and reduce frictional heating. Reduce in [26] strength and load-carrying capacity

In this work, the focus is on carbon-based reinforcements, specifically in SCF [29][31], GO [28], [31]-[33] and ND [31], [34] due to excellent tribological performance identified in previous studies.

\subsubsection{Short carbon fibers}

A fiber that is composed of at least $92 \mathrm{wt} \%$ of Carbon is defined as a carbon-fiber (CF) [35]. They exhibit excellent tensile properties, thermal and electrical conductivities, and good creep resistance [36]. Thus, CF reinforced materials have applications in various industries, such as aerospace, automobile, military and offshore [37].

It has a graphite-like crystal structure (Fig 2.5.1), composed of layers of hexagonally arranged carbons. Carbon atoms within layers are bonded by strong $\mathrm{sp}^{2}$ covalent bonds, whereas between layers the atoms are bonded by weak Van der Waals forces [38].

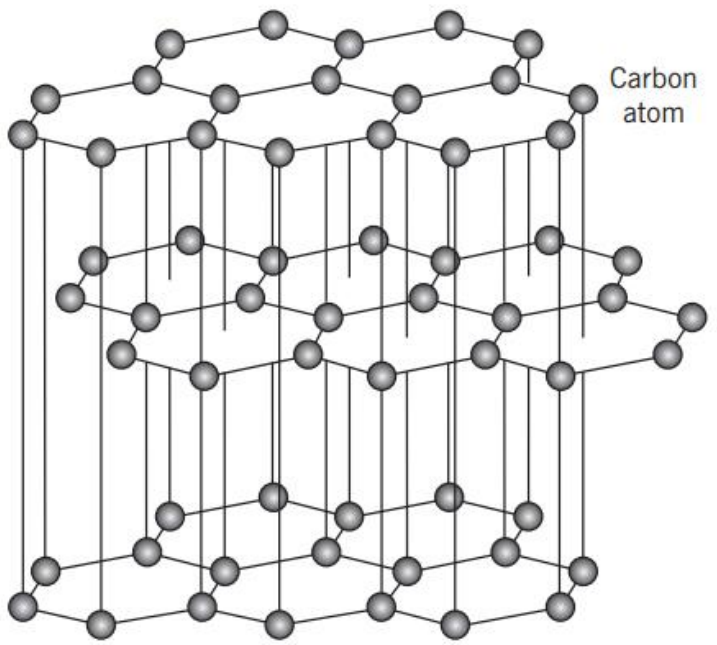

Figure 2.5.1 Crystal structure of graphite [38].

Nowadays polyacrylonitrile (PAN) and mesophase pitch (MP) are the two most important precursors to the production of $\mathrm{CF}$, where the first is the most commercially 
used. The mechanical [39], thermal [40] and electrical properties of the CF are affected by many factors such as defects, crystallinity, and orientation, all of which are dependent on the manufacturing procedure. For a summary of the effects and explanation of CF, properties refer to Huang's study [36].

SCF (average length of less than $10 \mathrm{~mm}$ ) are nothing more than short length $\mathrm{CF}$, which were developed to ease and reduce the price of fiber-reinforced composites. SCF are popularly used as polymer matrix reinforcements because they allow for the design of components of complex geometry, as well as exhibit excellent thermal, mechanical and electrical properties, and have a low tendency to agglomerate [41], [42].

Chukov et al. studied the structural, mechanical and tribological performance of UHMWPE reinforced with SCF. Their results showed an increase in yield strength and Young's modulus and a decrease in the strain rate with increasing CF content, which meant an improvement in the structural and mechanical properties, as well as improvement in the creep behavior of the composites. However, on the contrary of the mechanical properties, the tribological behavior did not follow the same pattern. The coefficient of friction for reinforced UHMWPE showed improvement compared to unfilled for dry conditions for all the compositions tested. Regarding wear, all the composites showed improved performance if compared to unfilled polymer, but increasing the $\mathrm{CF}$ content above $8 \mathrm{wt} \%$ showed to decrease the reinforcement performance [41].

Dangsheng also studied the tribological behavior of CF reinforced UHMWPE. He studied both dry and lubricated metal-composite contact and concluded that water lubricated contacts show lower friction and wear than pure UHMWPE. He also identified abrasive wear as the dominant wear mechanism of CF reinforced materials [43].

\subsubsection{Graphene Oxide}

GO is a 2D form of oxidized graphene. It is synthesized by treating graphite with oxidizers, such as a combination of potassium permanganate and sulfuric acid (Hummers method) [44]. The treatment with oxidizers introduces functionalized oxygen atoms on graphite, changing its structure, making the material hydrophilic and dispersible in water solutions, due to the addition of polar groups to an originally nonpolar material [45]. However, the functionalization of the surface compromises the structure of the graphene resulting in a structurally imperfect material, with lower physical properties if compared to graphene. The chemical structure of GO is shown in Fig 2.5.2.

GO flakes can be manufactured in various sizes (flakes can vary from few $\mathrm{nm}$ to $\mathrm{mm}$ ) and chemical compositions, which translates into excellent mechanical and electrical properties, high specific surface area and good interfacial adhesion [46]. Thus, GO is a potential material for different fields such as electronics, composite materials, biomedical and various tribological applications. 


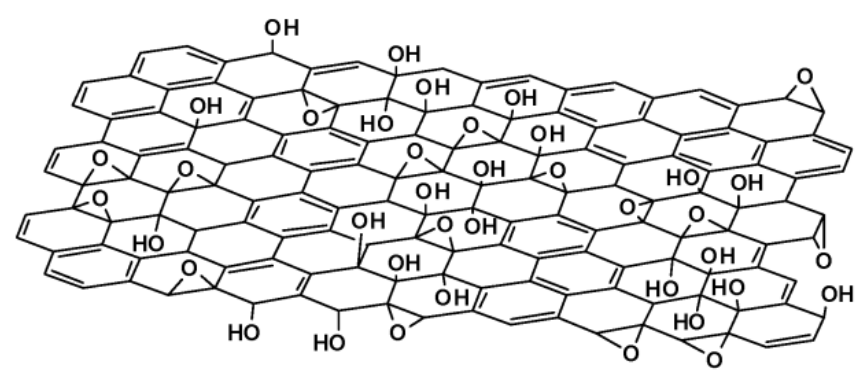

Figure 2.5.2 Chemical structure of GO based on the Lerf-Klinowski model with epoxy and hydroxyl groups functionalizing the surface [46].

Since the discovery of graphene, it has been the object of research in many different fields, and tribology is one of them. Tai et al. studied the tribological behavior of UHMWPE reinforced with GO nanosheets in dry sliding conditions. Their results showed an increase in the coefficient of friction, and reduction of the wear volume and rate. They also identified that adding more than $0.7 \mathrm{wt} \%$ of GO would not improve the wear performance of the composite due to agglomeration of GO nanosheets in the UHMWPE matrix, which hinders their beneficial effect [28]. Similarly, Suñer et al. identified that adding more than $0.5 \mathrm{wt} \%$ of GO would hinder the improvement of the mechanical and thermal properties of the GO reinforced UHMWPE [32].

Golchin et al. evaluated the tribological performance of multi-walled CNT and GO reinforced UHMWPE in water-lubricated contacts. They concluded that both composites exhibited lower friction and wear rates in comparison to unfilled UHMWPE, which was attributed to the good boundary lubrication behavior of the reinforced UHMWPE [33]. The lubricant effect of those fillers was previously reported by YuHong et al. [47].

\subsubsection{Nanodiamonds}

ND is a form of OD carbon allotrope that can be found naturally and manufactured in a laboratory. They are synthesized by using high energy techniques, such as detonation (Fig 2.5.3), plasma-assisted chemical vapor deposition (PA CVD), laser ablation, ion radiation of graphite and others [48].

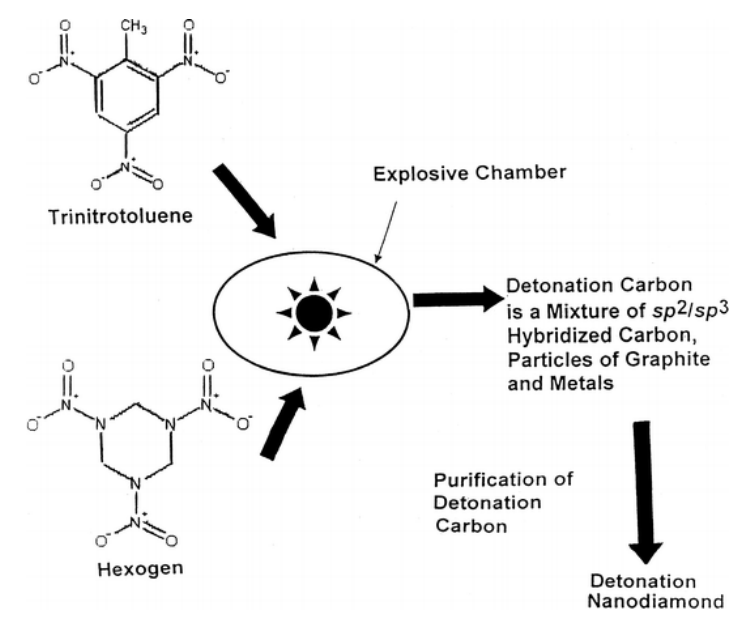

Figure 2.5.3 Detonation scheme for ND synthesis [49].

Bulk diamond exhibit excellent mechanical, electrical, chemical and thermal properties. These include but are not limited to hardness, Young's modulus, chemical 
stability and high thermal conductivity [38], [50]. ND retain most of those superior properties and delivers them in nanoscale [48], which makes it an excellent candidate for electrical, biomedical and tribological applications. Also, it displays a unique feature if compared to other carbon-based materials (i.e., MWCNT and graphite), which is that it allows for several functional groups to be attached to its surface. This feature allows for more versatile and complex functionalization, therefore increasing the potential application [51].
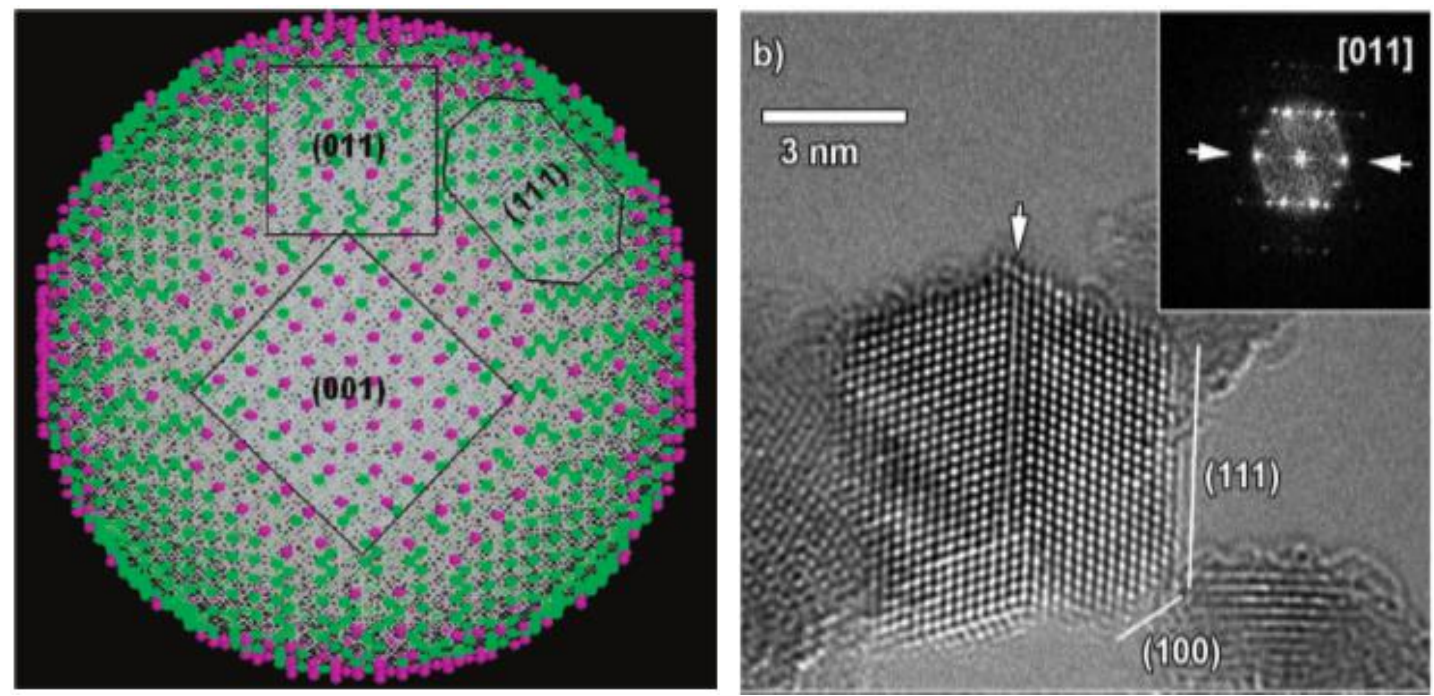

Figure 2.5.4 (Left) Schematic of a near-spherical diamond particle. (Right) Typical ND particle synthesized by detonation [52].

Despite having superior properties and ease of functionalization, ND particles tend to agglomerate, forming larger aggregates of ND, which hinders natural properties and requires de-aggregation procedures. These procedures increase the processing time and complexity.

NDs are a novel material, and limited studies have been performed with it, especially when it comes to using it as a polymer reinforcement. Ivanov et al. studied the effect of detonated ND and PTFE as additives for oil-based lubricants. Their results revealed between $80-90 \%$ decrease in the coefficient of friction between un-quenched and quenched steels, as well as a significant reduction in wear [53].

Chou and Lee also studied the tribological performance of ND-dispersed lubricants on carbon steel and aluminum alloy. They concluded that ND particles improved the tribological performance of the contacts, especially in reducing wear. However, they identified different mechanisms for different mating surfaces. For carbon steel surfaces, the reduction of wear was caused not only by the increase in the viscosity of the lubricant due to ND particles but also due to the increase of the contact surface toughness. For aluminum surfaces, changes in the viscosity of the lubricant dominated the observed reduction in wear [54].

Golchin et al. used ND as reinforcement for UHMWPE matrix. They studied the tribological behavior of the polymer composite in water-lubricated contacts and observed around a $72 \%$ reduction in wear and $24 \%$ reduction in coefficient of friction if compared to unfilled UHMWPE. They attributed the improvements to the boundary lubrication action of nanoparticles, which may act as 'ball bearings,' shifting the contact from pure sliding to a rolling-sliding motion [34]. 


\section{Research gap}

UHMWPE has been thoroughly studied since the 1960s due to its balanced mechanical and thermal properties, which provided versatility in its application. Individual effects of moisture absorption [20], [23], [55], gamma radiation [56]-[59] and temperature [60] on the structural integrity, mechanical properties, thermal performance and tribological performance of UHMWPE have been studied and reported. However, the correlation between the effect of multiple simultaneous parameters on the tribological performance is still lacking.

As previously mentioned, different reinforcement and fillers are used to improve the tribological performance of the UHMWPE[23], [33], [34]. Recent research has identified that combining macro and nano-reinforcements has significantly improved the friction and wear performance of the composites. Results from Vadivel et al. showed that hybrid UHMWPE, reinforced with SCF, GO, and ND exhibited $21 \%$ reduction in friction and $15 \%$ lower specific wear rate if compared to unfilled UHMWPE [31]. The improvement suggests a synergistic behavior between micro (SCF) and nano (GO and ND) fillers, which is an essential advancement for polymer composites development and applications. Still, the development of multiscale hybrid reinforced composites is new research, and further advancements are needed.

Despite the increased interest in hybrid polymer composites development, manufacturing and applications, there are limited tribological investigations on their performance. The effect of hygrothermal aging on the properties and performance of those materials has not been thoroughly studied, which is relevant when considering them for water-lubricated tribological applications.

\section{Purpose of the study}

Therefore, considering the lack of research on the combined effect of water and temperature on the aging and tribological performance of UHMWPE composites. The purpose of this work is to experimentally investigate the effect of hygrothermal aging, which is the combination of water absorption and temperature, on the tribological performance of hybrid UHMWPE composites. The objectives of this work can be divided as follows:

- Evaluate the effects of hygrothermal aging on the structure of the composites;

- Study the effects of aging on the surface conditions of the materials; and

- Evaluate the effect of aging on the tribological performance of UHMWPE composites.

\section{Experimental work}

\subsection{Materials}

\subsubsection{Polymer composites}

The chosen polymer matrix is UHMWPE based on previous expertise on handling and testing it, versatility on applications and to continue previous tribological studies performed by Tribolab at the Luleå University of Technology. 
MIPELON ${ }^{T M}$ UHMWPE XM-220, from Mitsui Chemicals, was the UHMWPE used. Table 5.1.1 presents the physical properties of the supplied UHMWPE according to manufacturer datasheet.

Table 5.1.1 Physical properties of MIPELON ${ }^{T M}$ UHMWPE XM-220.

\begin{tabular}{ll}
\hline Property & Value \\
\hline Molecular weight $\left[\mathrm{gmol}^{-1}\right]$ & $200 \mathrm{E} 4$ \\
Density $\left[\mathrm{gm}^{-3}\right]$ & $9.4 \mathrm{E}-1$ \\
Melting point $\left[{ }^{\circ} \mathrm{C}\right]$ & 136 \\
Average particle size $[\mu \mathrm{m}]$ & 30
\end{tabular}

As previously discussed, tribological properties of UHMWPE can be significantly improved using reinforcements. The fillers used in this work were carbon-based, them being SCF, GO and ND. These were chosen because of previous expertise from the laboratory and successful use of those materials for enhancing the tribological behavior of UHMWPE matrix [31], [33], [34].

Tenax® -A HT M100 100mu, from Toho Tenax, was the SCF used for this work. It is a milled CF with excellent processability and resin compatibility. Table 5.1.2 presents some properties of the SCF according to the manufacturer datasheet.

Table 5.1.2 Physical properties of Tenax ${ }^{\circledR}$-A HT M100 100mu.

\begin{tabular}{ll}
\hline Characteristic & Value \\
\hline Fiber length $[\mu \mathrm{m}]$ & 100 \\
Typical bulk density $\left[\mathrm{gcm}^{-3}\right]$ & $350 \mathrm{E}-3$ \\
Filament diameter $[\mu \mathrm{m}]$ & 7
\end{tabular}

ND-COOH-30nm, from Adámas Nanotechnologies, was the ND used for this work. It is a commercially available carboxylated detonation ND. Table 5.1.3 shows the characteristics of the material according to the manufacturer datasheet. GO was supplied by Nanoinnova Technologies, consisting of monolayer sheets of 0.7-1.2 nm thickness with a particle length of 3-5 $\mu \mathrm{m}$.

Table 5.1.3 Characteristics of ND-COOH-30nm.

\begin{tabular}{ll}
\hline Characteristic & Value \\
\hline Ash content [\%] & 0.6 \\
Average particle size $[\mathrm{nm}]$ & $\sim 4-5$ \\
Average aggregate size $[\mathrm{nm}]$ & 30 \\
\hline
\end{tabular}

Five different compositions (Table 5.1.4) were mixed from the primary materials, these followed the work previously performed by Vadivel [61], where he studied the manufacturing of the hybrid composites by compression molding. The focus of this work was not on producing the composites, but evaluating its performance experimentally, therefore, the manufacturing procedure will not be described in this work, for further information see [61]. 
Table 5.1.4 Composite blends used.

\begin{tabular}{ccccc}
\hline \multirow{2}{*}{ Designation } & ND & GO & SCF & UHMWPE \\
\hline UHMWPE & 0.0 & 0.0 & 0.0 & 100.0 \\
SCF & 0.0 & 0.0 & 10.0 & 90.0 \\
GO & 0.0 & 1.0 & 0.0 & 99.0 \\
ND & 1.0 & 0.0 & 0.0 & 99.0 \\
GO+ND+SCF & 0.5 & 0.5 & 10.0 & 89.0 \\
\hline
\end{tabular}

\subsubsection{Countersurface}

The countersurface chosen for tests was Inconel 625, which is a nickel-chromium alloy. It is a material with high strength, nonmagnetic, corrosion- and oxidation resistant alloy that finds use in various aggressive environments. Due to its excellent properties, it finds applications in various fields, such as energy generation, marine, chemical and aerospace [62]. The composition of the alloy is given shown in table 5.1.5 and follows the standard ASTM B446-03/2014 "Standard Specification for Nickel-ChromiumMolybdenum-Columbium Alloy (UNS N06625), Nickel-Chromium-MolybdenumSilicon Alloy (UNS N06219), and Nickel-Chromium-Molybdenum-Tungsten Alloy (UNS N06650) Rod and Bar".

The Inconel was used as discs of $1.5 \mathrm{~mm}$ thickness and $65 \mathrm{~mm}$ radius. The disc surface was ground using SiC papers of grit P\#120 using a Buehler Metaser 250 grinder/polisher to obtain consistent surface topography.

Table 5.1.5 Composition of Inconel 625 [63].

\begin{tabular}{llllllllllllll}
\hline Limits & $\mathrm{Cr}$ & $\mathrm{Mo}$ & $\mathrm{Co}$ & $\mathrm{Nb}+\mathrm{Ta}$ & $\mathrm{Al}$ & $\mathrm{Ti}$ & $\mathrm{C}$ & $\mathrm{Fe}$ & $\mathrm{Mn}$ & $\mathrm{Si}$ & $\mathrm{P}$ & $\mathrm{S}$ & $\mathrm{Ni}$ \\
\hline Min [\%wt] & 20 & 8 & -- & 3.15 & -- & -- & -- & -- & -- & -- & -- & -- & Bal. \\
Max [\%wt] & 23 & 10 & 1 & 4.15 & 0.4 & 0.4 & 0.1 & 5 & 0.5 & 0.5 & 0.015 & 0.015 & Bal. \\
\hline
\end{tabular}

\subsubsection{Sample preparation}

The materials manufactured by compression molding were then cut into smaller samples for the subsequent experiments. Two sample sizes were used for the hygrothermal aging analysis as shown in Fig 5.1.1. The different uses of the samples will be discussed in section 5.2 . 

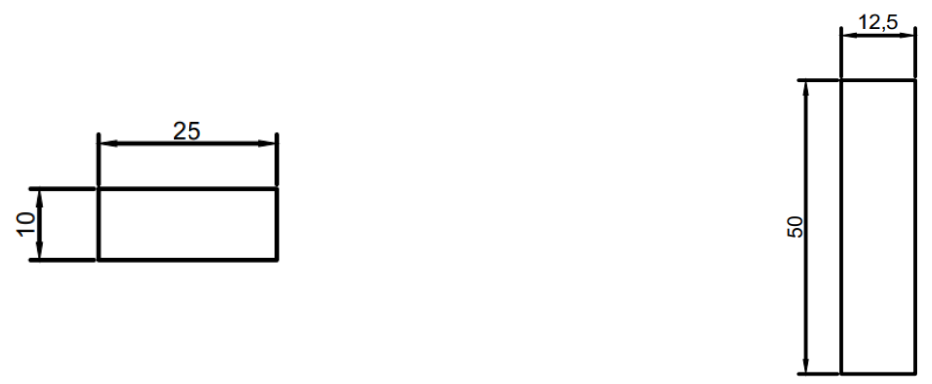

Figure 5.1.1 (Left) Sample for thermal characterization. (Right) Aging sample for tribological testing. Dimensions shown are presented in millimeters.

After the samples (Fig 5.1.1 right) were aged, they were sectioned into pins with 4.1 $\mathrm{mm}^{2}$ of surface area so that they would fit into the tribometer sample holder.

\subsection{Hygrothermal aging}

Samples shown in Fig 5.1.1 were aged in distilled water and at two different temperatures (room temperature and $80{ }^{\circ} \mathrm{C}$ ). Water was chosen due to the interest in studying the effects of extended exposure of the composites to the water.

Aging was performed at two temperatures, room temperature, and $80^{\circ} \mathrm{C}$. The first was chosen to serve as a benchmark for the other condition, $80{ }^{\circ} \mathrm{C}$ was chosen based on the maximum recommended operating temperature for UHMWPE according to several suppliers.

As mentioned in section 5.1, two different aging procedures were followed. One (Procedure 1) had the goal of evaluating the thermal and structural changes on the samples (Fig 5.1.1 left), the other (Procedure 2) to evaluate the effects of aging on the tribological behavior of the polymer composites. It has been shown that UV radiation increases the aging intensity [64], [65]. Therefore, the experiment was performed in closed containers away from UV radiation. Table 5.2.1 presents the parameters used for Procedure 1 aging and table 5.2.2 for the parameters of Procedure 2.

Different analysis techniques were used to evaluate the samples from Procedure 1 and 2 (Table 5.2.3). Each technique is explained in its correspondent section from this report. It is important to reiterate that samples from Procedure 2 were subsequently used for tribological investigations (section 5.3).

Table 5.2.1 Parameters for aging procedure 1.

Procedure 1 aging parameters

\begin{tabular}{ll}
\hline Duration [days] & 120 \\
Medium & Distilled water \\
Container volume $[\mathrm{ml}]$ & 50 \\
Sample dimensions $[\mathrm{mm}]$ & $10 \times 25 \times 5$ \\
Volume $[\mathrm{ml} / \mathrm{sample}]$ & 30 \\
Temperature $\left[{ }^{\circ} \mathrm{C}\right]$ & $\sim 21-23$ \\
\hline
\end{tabular}


Table 5.2.2 Parameters for aging procedure 2.

\begin{tabular}{ll}
\hline & Procedure II aging parameters \\
\hline Duration [days] & 120 \\
Medium & Distilled water \\
Container volume $[\mathrm{ml}]$ & 500 \\
Sample dimensions $[\mathrm{mm}]$ & $12.5 \times 50 \times 5$ \\
Volume $[\mathrm{ml} / \mathrm{sample}]$ & $\sim 250$ \\
Temperature $\left[{ }^{\circ} \mathrm{C}\right]$ & $\sim 21-23$ \\
\hline
\end{tabular}

Table 5.2.3 Analyses used for each aging procedure

\begin{tabular}{lcc}
\hline Analysis & Procedure 1 & Procedure 2 \\
\hline Water intake (Section 5.2.1) & No & Yes \\
Wettability (Section 5.2.2) & No & Yes \\
FTIR spectroscopy (Section 5.2.3) & Yes & Yes \\
DSC (Section 5.2.4) & No & Yes \\
TGA (Section 5.2.5) & Yes & No \\
\hline
\end{tabular}

\subsubsection{Water intake}

The analysis of the water intake was performed based on the standard ASTM D522992 "Standard Test Method for Moisture Absorption Properties and Equilibrium Conditioning of Polymer Matrix Composite Materials." However, it is important noting that a few of the assumptions from the standard were not followed, these were:

- A minimum sample mass of $5 \mathrm{~g}$;

- Use of a traveler coupon to compensate for the lower mass;

- Characteristic measurement period;

- Square-shaped sample.

These were not followed for a couple of different reasons. First, we wanted to simulate different sample geometries, which is beneficial when considering real applications. Secondly, the size of aging containers available limited the choice of sample size, and consequently the mass.

After samples were sectioned into Fig 5.1.1 (right) shape, the lateral faces were ground using P\#600 SiC paper to obtain smooth lateral surfaces. After grinding the samples were cleaned in an ultrasonication ethanol bath for 30 minutes. After cleaning, the samples were dried in air for 6 hours at room temperature.

The next step was to weight the samples using a balance with $0.01 \mathrm{mg}$ precision. Each measurement was performed 5 times per sample, and the dried sample masses $\left(M_{\circ}\right)$ were noted. After the dried samples were weighted, they were placed into the water bath. The ones used for higher temperature analysis were placed in a pre-heated furnace at $80{ }^{\circ} \mathrm{C}$. 
The mass measurement interval was 7 days, and a total number of 16 measurement periods were done, resulting in 112 days of exposure time. For every measurement period, the samples aged at room temperature were measured first and then higher temperature ones. The weighting was performed using the following procedure:

- Cleaning the balance;

- Removal of the sample from bath and put it in a specimen bag (sealable, flexible and moisture free);

- Keep sample in the specimen bag for 2 minutes for room temperature aged samples, and for 5 minutes for elevated temperatures;

- Remove the samples from specimen bag and gently wipe the surfaces with a fiber-free cloth to remove all the excess moisture;

- Weight the samples using a $0.01 \mathrm{mg}$ precision balance;

- Repeat measurements 5 times;

- Calculate the average of the five measurements and take note of it $\left(\mathrm{M}_{\mathrm{t}}\right)$;

- Calculate the weight variation by using equation (1);

$$
\Delta M_{\%}=\frac{M_{t}-M_{0}}{M_{0}} * 100
$$

- Repeat the weekly measurements until 16 measurements are achieved.

\subsubsection{Wettability and surface energy}

Contact angle measurements were performed to study the wettability of the composites. Attension Theta optical tensiometer, from Biolin Scientific, was used for the measurement of the contact angles. Sessile drop experiment was the method used for the measurements.

Two different fluids were used for the measurements, distilled water, and diiodomethane. Water was chosen because it is the most common and widely used polar fluid for contact angle measurements. Also, since we were interested in waterlubricated conditions, it is interesting to evaluate how the composites behave with water. Diiodomethane was chosen because it is a non-polar fluid, and therefore would allow for the calculation of the surface free energy (SFE). Table 5.2.4 shows the relevant parameters used for the sessile experiment.

Table 5.2.4 Parameters used for the sessile experiment.

\begin{tabular}{lcc}
\hline & Water & Diiodomethane \\
\hline Drop volume $[\mu \mathrm{l}]$ & 3 & 1 \\
Measurement time $[\mathrm{s}]$ & 10 & 10 \\
Repetitions & $10 / 5^{*}$ & 5 \\
\hline *Samples corresponding to aging procedure 1 & &
\end{tabular}

After measuring the contact angles with both fluids, the SFE was calculated. There are different theories for calculating it, but one of the most common is OWRK, which allows for the calculation of polar and dispersive components of the SFE by using two or more different fluids to measure the contact angles [66]. Equation (2) describes the OWRK method for calculating the polar and dispersive surface energy components of the composites. 


$$
\gamma_{l} *\left(1+\cos \theta_{l}\right)=2 * \sqrt{\gamma_{s}^{p} \gamma_{l}^{p}}+2 * \sqrt{\gamma_{s}^{d} \gamma_{l}^{d}}
$$

Where ' $\gamma_{1}$ ' is the surface tension of the liquid, ' $\theta_{1}$ ' is the contact angle and ' $\gamma_{\mathrm{s}}$ ' is the surface energy of the solid. The indexes ' $p$ ' and ' $d$ ' correspond to the polar and dispersive components of the surface energy and tension.

As previously discussed and observed in equation 2, there are two unknowns when trying to calculate the surface energy for a solid surface. Therefore, the contact angle with two different fluids is needed so that information can be input in the model. Table 5.2.5 presents the surface tension information of water and diiodomethane.

Table 5.2.5 Surface tension information of water and diiodomethane.

\begin{tabular}{lcc}
\hline & Water & Diiodomethane \\
\hline Polar surface tension $\left[\mathrm{mNm}^{-1}\right]$ & 21.80 & 0.00 \\
Dispersive surface tension $\left[\mathrm{mNm}^{-1}\right]$ & 51.00 & 50.80 \\
Total surface tension $\left[\mathrm{mNm}^{-1}\right]$ & 72.80 & 50.80 \\
\hline
\end{tabular}

Studying the wettability and surface energy would allow the understanding of how the composite reacts with a fluid/environment. For example, materials with high surface energy, especially with higher polar contents, tend to react more with the liquid and consequently, the liquid tends to spread over the surface (hydrophilic behavior). On the other hand, materials with low surface energy tend to have poor wetting (hydrophobic), which may be important when talking about lubricated contacts. The wettability analysis was performed before aging, 30, 60 and 120 days aged.

\subsubsection{FTIR}

FTIR was performed to examine and detect possible chemical changes in the composites due to hygrothermal aging. The technique consists of measuring the infrared absorption spectrum generated by the vibration of molecules, which is characteristic for each compound. For further theory on FTIR, refer to "Infrared spectroscopy: fundamentals and applications" by Barbara Stuart [67].

The analyses were carried out on a Bruker Vertex 80v FTIR spectrometer in ATR mode, mid-IR range $\left(4000-400 \mathrm{~cm}^{-1}\right), 4 \mathrm{~cm}^{-1}$ resolution and a total of 128 scans. All the samples were analyzed before aging, after 60 and 120 days aged.

\subsubsection{DSC}

DSC analyses were performed using a Mettler Toledo DSC to determine the degree of crystallinity and melting temperature of the polymer composites before and after aging. This information is relevant as it holds information about the polymer structure, and it has been shown that the degree of crystallinity of polymers affect their mechanical properties and consequently their tribological performance [68].

The procedure described at ASTM F2526 "Standard Test Method for Measurement of Enthalpy of Fusion, Percent Crystallinity, and Melting Point of Ultra-High-Molecular Weight Polyethylene using Differential Scanning Calorimetry" was followed for the measurement. Samples used had a mass between 6 and $10 \mathrm{mg}$, which were placed into a non-hermetic aluminum crucible. The whole measurement was performed with closed 
crucible with a small hole in the lid, under a purge of nitrogen and an empty crucible as a reference. A summary of the method described at the standard is shown below:

1. Heating the sample from $25{ }^{\circ} \mathrm{C}$ to $200{ }^{\circ} \mathrm{C}$, keeping the sample at the maximum temperature for 5 minutes, and cooling back to $25^{\circ} \mathrm{C}$. Both the heating and cooling rate were $10 \mathrm{Kmin}^{-1}$;

2. Heating from $25{ }^{\circ} \mathrm{C}$ to $200{ }^{\circ} \mathrm{C}$, with a rate of $10 \mathrm{Kmin}^{-1}$ to carry out the DSC measurement;

3. Cooling from 200 to $25^{\circ} \mathrm{C}$.

The results obtained from the measurement were the degree of crystallinity $\left(\mathrm{X}_{\mathrm{c}}\right)$ and the melting temperature, where the crystallinity is defined in equation (3) [69].

$$
X_{c}=\frac{\Delta H}{\left(1-W_{f}\right) * \Delta H_{100}} * 100
$$

Where ' $\Delta \mathrm{H}$ ' is the measured enthalpy of fusion, ' $\Delta \mathrm{H}_{100}$ ' is the enthalpy of fusion of $100 \%$ crystalline PE, which is estimated to be $289 \mathrm{~J} / \mathrm{g}$. For the calculation of the crystallinity, the baseline used was set in between $50{ }^{\circ} \mathrm{C}$ and $160{ }^{\circ} \mathrm{C}$.

\subsubsection{TGA}

TGA analysis was carried out in $\mathrm{N}_{2}$ atmosphere on a $T G Q 500$, from TA Instruments, between $30^{\circ} \mathrm{C}$ and $600{ }^{\circ} \mathrm{C}$ at a heating rate of $10^{\circ} \mathrm{C} / \mathrm{min}$. This analysis was performed to evaluate the thermal stability of the UHMWPE composites before and after aging. The thermal stability was evaluated according to the weight loss of the samples. The results are presented according to temperature for which the samples lost 10, 20, $50 \%$ of weight, and the remainder of mass.

\subsection{Tribological evaluation}

After aging the samples (Fig 5.1.1 right), they were sectioned into $4.1 \times 4.1 \times 4.1 \mathrm{~mm}^{3}$ pins that were used for tribological investigations. The experiment was performed in three different timesteps, before aging, 60, and 120 days aged. Tribological tests were used to study the friction and wear of the composites in water-lubricated sliding conditions, which could serve as a simplification for bearings applications.

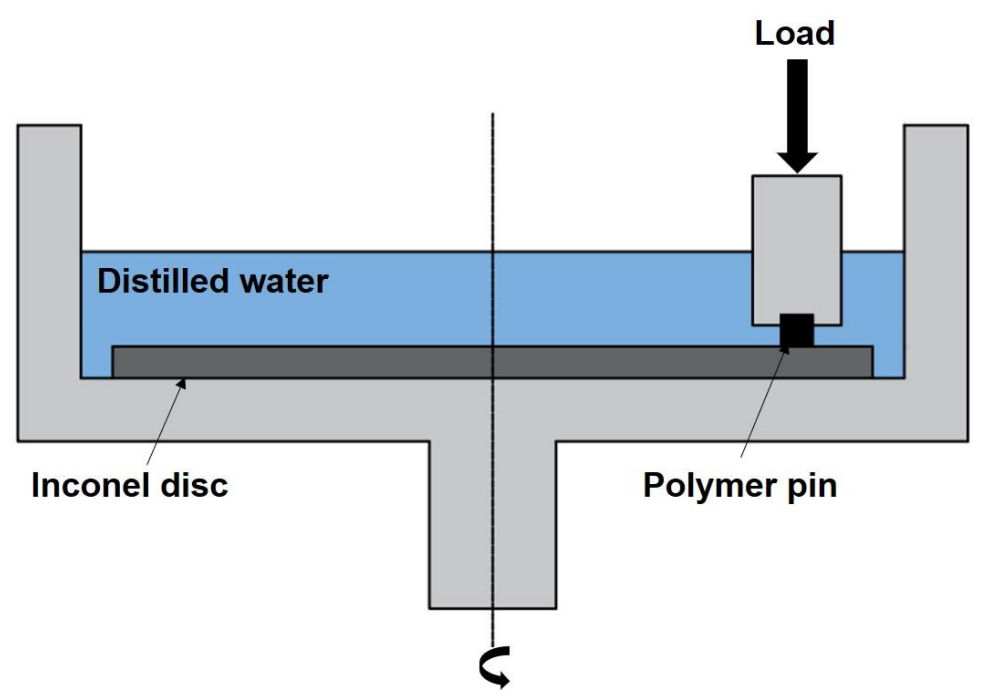

Figure 5.3.1 Schematic of the pin-on-disc configuration. 
The tests were performed using a Plint TE67 pin-on-disc tribometer (schematically shown in Fig. 5.3.1), from Phoenix Tribology, at room temperature $\left(\sim 21-23{ }^{\circ} \mathrm{C}\right)$. The applied load was $9 \mathrm{~kg}$, which resulted in an apparent contact pressure of $5 \mathrm{MPa}$ considering the face area of the polymer pin. This contact pressure was chosen considering the lower operating pressure for hydropower applications [9], as well as to avoid the excessive creep and accelerate the testing of the polymer composites.

The sliding speed during the test was $0.13 \mathrm{~m} . \mathrm{s}-1$, which was chosen based on the lowest possible rotational speed of the tribometer that would result in smooth motion. The countersurface preparation procedure explained in section 5.1.2 resulted in average surface roughness $(\mathrm{Ra})$ of approximately $0.1 \mu \mathrm{m}$. The tests were performed for 4 hours, and each test was repeated 3 times to obtain the average and standard deviation. Table 5.3.1 summarizes the test conditions used for the experiments.

Table 5.3.1 Pin-on-disc test conditions.

\begin{tabular}{lll}
\hline Parameter & Value & \\
\hline Load (Deadweight) & $9 \mathrm{~kg}$ & \\
Apparent contact pressure & $5 \mathrm{MPa}$ & \\
Temperature & $\sim 23^{\circ} \mathrm{C}$ & \\
Sliding speed & $0.13 \mathrm{~m} / \mathrm{s}$ & \\
Duration & 4 hours & \\
Timestep & Before aging & \\
Pin surface Ra & $\sim 0.25 \mu$ days aged & \\
Countersurface Ra & $\sim 0.1 \mu \mathrm{m}$ & \\
Lubricant & Distilled water & \\
\hline
\end{tabular}

\subsubsection{Friction}

The friction was evaluated according to the friction force measured during the tribological evaluation. The measured friction force was then used to calculate the coefficient of friction $(\mu)$ based on Coulomb's law, as shown in equation 4.

$$
F_{f}=\mu *(P * g)
$$

Where ' $\mathrm{P}$ ' is the applied load in kilograms, and ' $\mathrm{g}$ ' is the acceleration of gravity at sea level in $\mathrm{m} . \mathrm{s}^{-2}$. Where the coefficient of friction was calculated considering steady friction conditions, which were achieved after 2 hours of the test.

\subsubsection{Wear}

The analysis of wear was performed by measuring the linear displacement of the polymer pins by using an LVDT. The displacement allowed the calculation of the specific wear rate by using equation 5 .

$$
S W R=\frac{W_{v}}{(P * g) * S}
$$

Where ' $\mathrm{W}_{\mathrm{v}}$ ' is the wear volume in $\left[\mathrm{mm}^{3}\right]$, and ' $\mathrm{s}$ ' is the sliding distance in [m]. SWR was calculated from the steady-state region of the real-time wear volume plots, as shown in figure 5.3.2. 


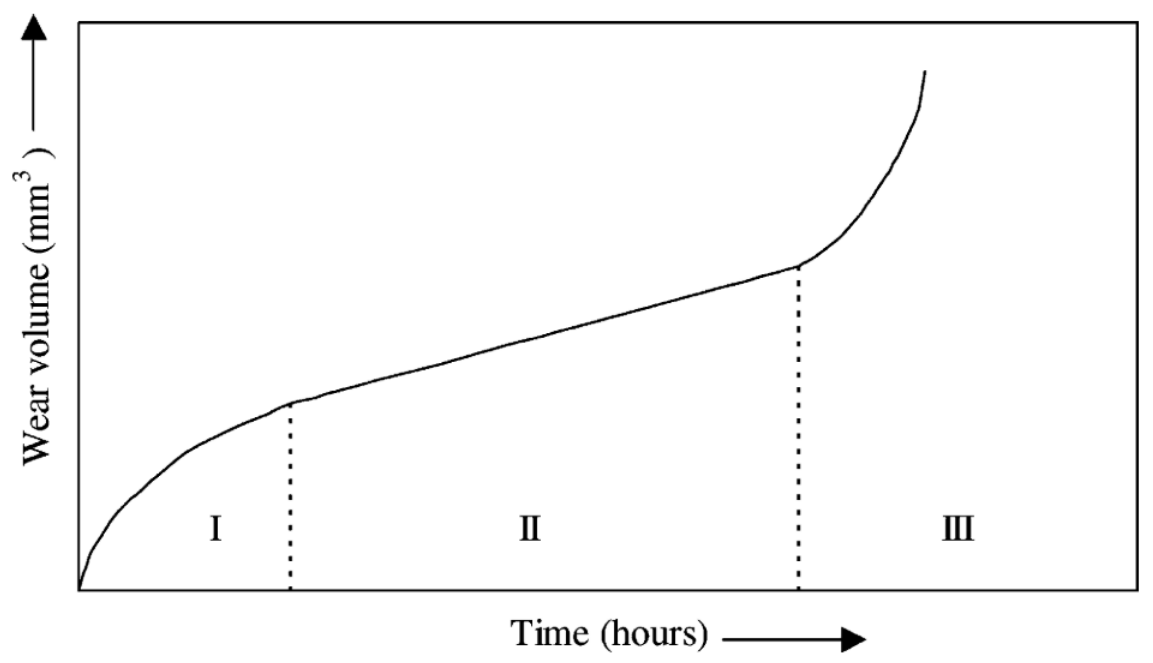

Figure 5.3.2 Wear behavior of a component. I. running-in; II. steady state wear; III. wear out zone [70].

\subsubsection{SEM/EDS}

The polymer pins and wear tracks were then analyzed using SEM coupled with EDS, Jeol JCM-6000 (Neoscope), for topographical and chemical analysis. These techniques were used to investigate the wear mechanism and formation of transfer film, which are relevant when trying to understand the tribological behavior of different composites. Backscattered electron image (BEI) and secondary electron image (SEI) were used to analyze the surfaces, where the first provides information on the atomic number and crystallographic information and the second topographical characteristics.

\section{Results and discussion}

The results and discussion will be divided into two main groups, one for the aging procedure I and the other for procedure II as described in sections 5.1 and 5.2.

\subsection{Aging procedure I}

\subsubsection{FTIR}

The ATR-FTIR spectra of unfilled and hybrid UHMWPE composites aged according to the procedure I are presented in Fig. 6.1.1 and 6.1.2 respectively. It is possible to identify characteristic UHMWPE peaks, which are $\mathrm{CH}_{2}$ stretching $\left(2840-2870 \mathrm{~cm}^{-1}\right.$, 2915-2940 $\left.\mathrm{cm}^{-1}\right), \mathrm{CH}_{2}$ scissor vibration (1440-1465 $\mathrm{cm}^{-1}$ ) and $\mathrm{CH}_{2}$ rock-like bending (720-725 $\left.\mathrm{cm}^{-1}\right)$ [55], [71]. However, for unfilled material aged at $80{ }^{\circ} \mathrm{C}$ other peaks appear at $1540-1575 \mathrm{~cm}^{-1}, 1020 \mathrm{~cm}^{-1}$, and $450 \mathrm{~cm}^{-1}$. These correspond to diketones, secondary alcohols and straight chain alkane skeleton vibration respectively [72], which are products of oxidation of UHMWPE as discussed by [60], [64], [73]. 


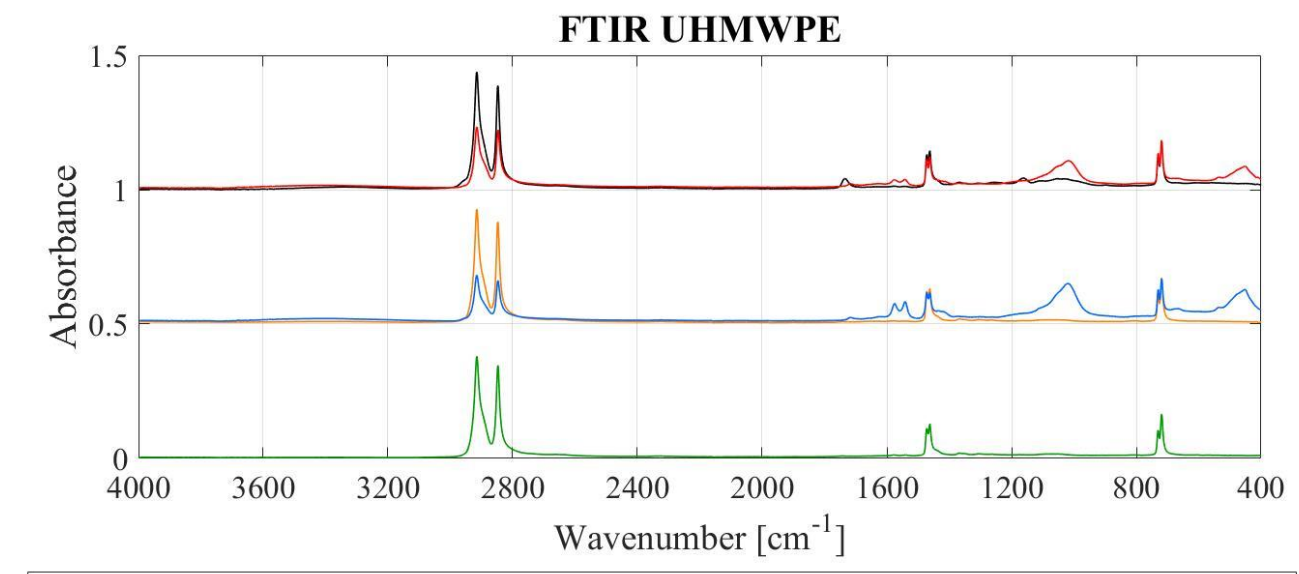

-Before ageing -60 days RT -60 days $80^{\circ} \mathrm{C}-120$ days RT -120 days $80^{\circ} \mathrm{C}$

Figure 6.1.1 ATR-FTIR spectra for unfilled UHMWPE.

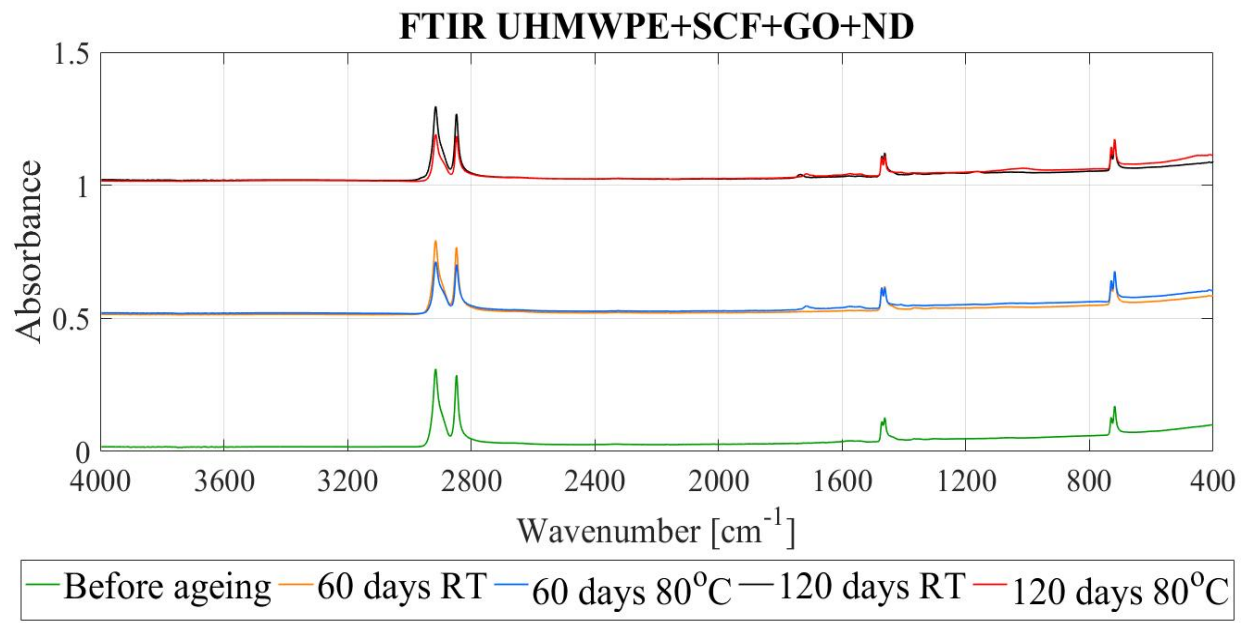

Figure 6.1.2 ATR-FTIR spectra for hybrid UHMWPE composites.

Analyzing both spectra, the peaks of oxidation products are either not present or of low intensity for the hybrid composite. The lower intensity or absence of the peaks indicates that hygrothermal aging lower effect in the hybrid composite, which demonstrated fewer oxidation products than the unfilled UHMWPE. Still, this improvement was not seen when evaluating composites reinforced with SCF, ND and GO separately (Fig. 6.1.3), which suggests a synergic effect of the micro and nano-reinforcements in increasing the oxidation resistance of the material. However, further investigations are needed to prove this mechanism. 


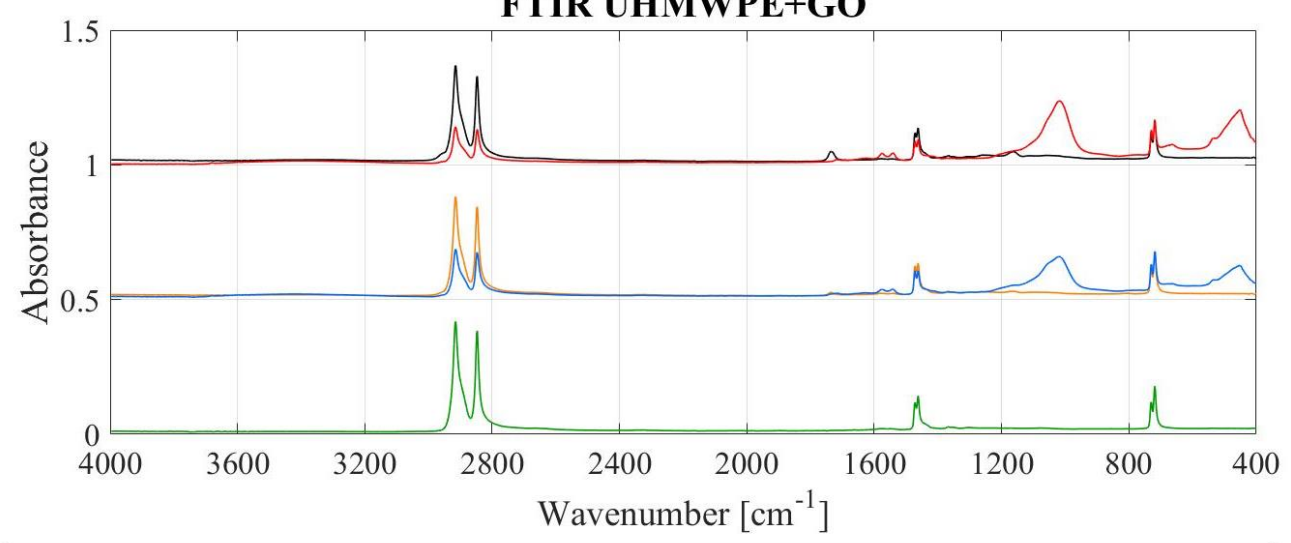

-Before ageing -60 days RT -60 days $80^{\circ} \mathrm{C}-120$ days RT -120 days $80^{\circ} \mathrm{C}$

b

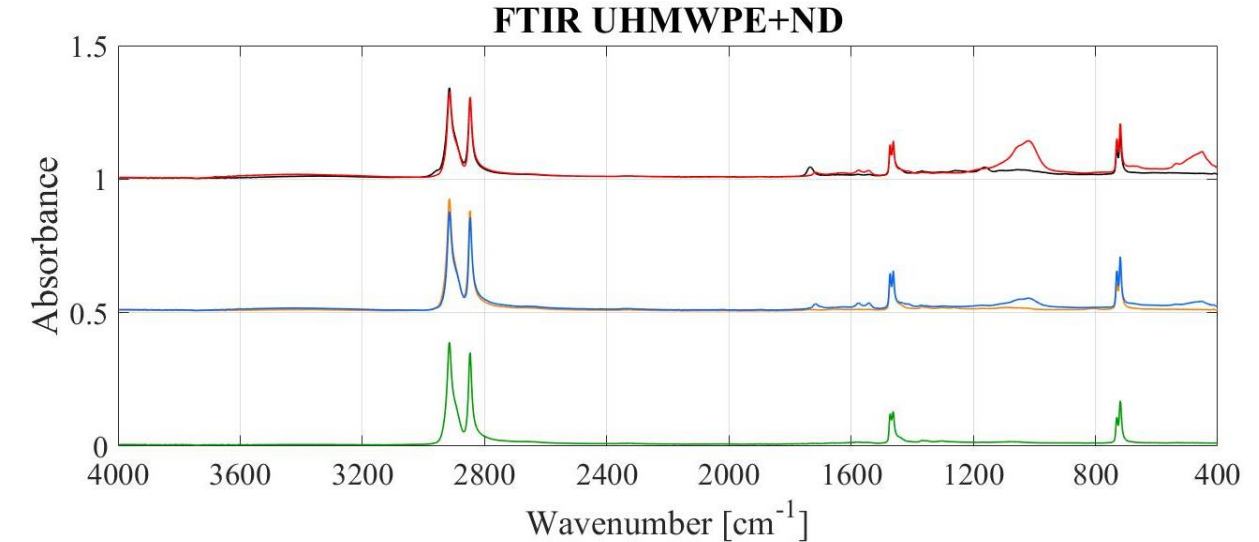

- Before ageing -60 days $\mathrm{RT}-60$ days $80^{\circ} \mathrm{C}-120$ days $\mathrm{RT}-120$ days $80^{\circ} \mathrm{C}$

c

FTIR UHMWPE+SCF

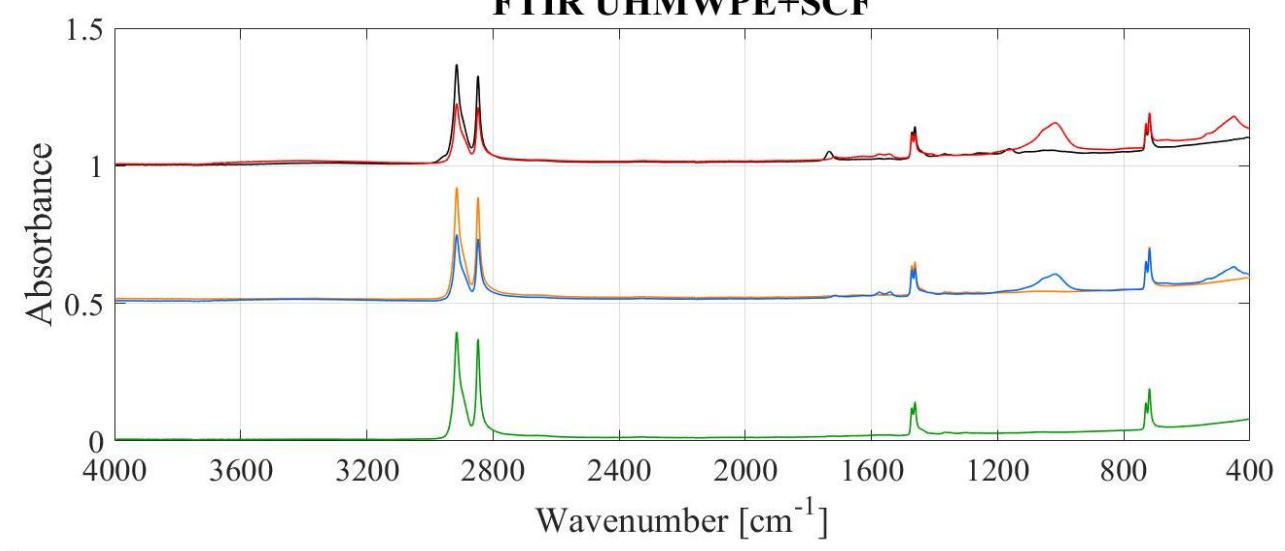

- Before ageing -60 days RT -60 days $80^{\circ} \mathrm{C}-120$ days RT -120 days $80^{\circ} \mathrm{C}$

Figure 6.1.3 ATR-FTIR for UHMWPE reinforced with micro and nano-sized fillers. (a) GO, (b) ND, and (c) SCF reinforced UHMWPE.

\subsubsection{TGA}

Decomposition curves for the materials in $\mathrm{N}_{2}$ atmosphere are presented in Fig. 6.1.4. The materials, except ND reinforced UHMWPE, showed similar degradation trends, but with different final residues. Different residues were expected as the composite materials contain carbon reinforcement particles, which are not degraded at $600{ }^{\circ} \mathrm{C}$. 
Hybrid composites exhibited the largest amount of residue, followed by SCF reinforced UHMWPE, both with higher content of fillers. ND reinforced material should be further investigated to understand its degradation mechanism.

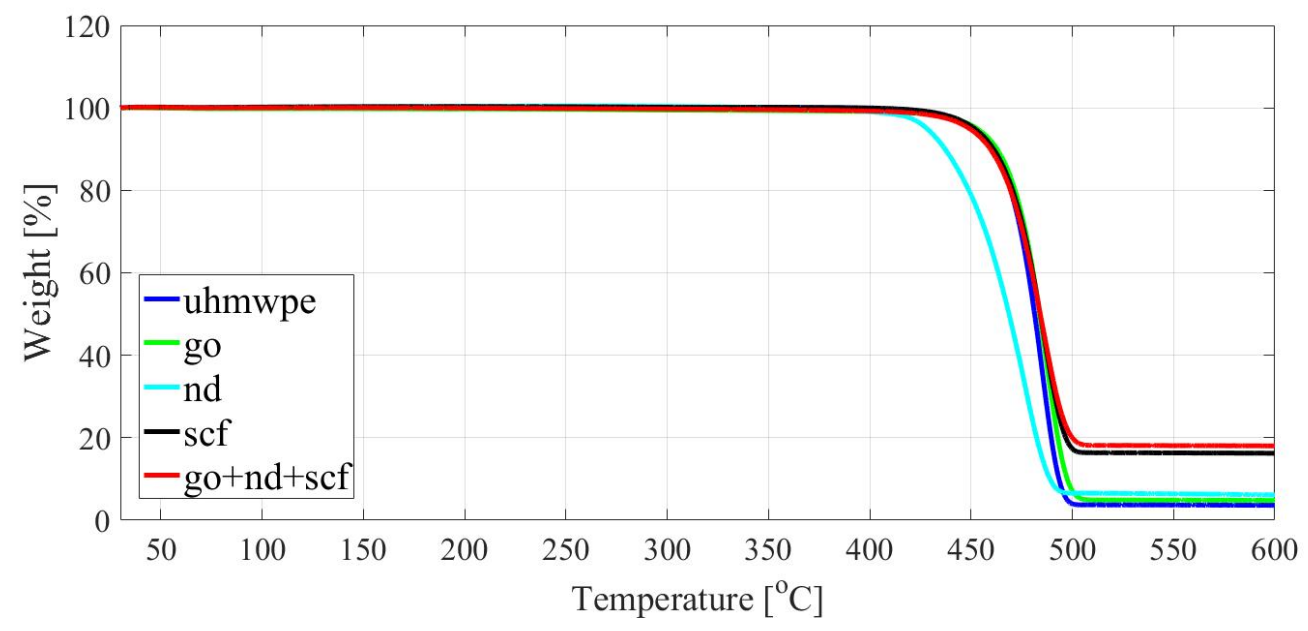

Figure 6.1.4 Decomposition curves for unaged materials.

Table 6.1.1 presents temperatures in which composites experience 10, 20, $50 \%$ of weight loss, and reached their final residue. The results indicate that aged samples were affected by the aging procedure.

Unfilled UHMWPE showed a significant decrease in the $10 \%$ weight loss temperature for both room and elevated temperature aging, which implies that structural or chemical changes occurred during aging, probably due to oxidation of the surfaces. Those changes were verified and identified by FTIR analysis (Fig. 6.1.1), which the presence of carbonyl groups of typical UHMWPE oxidation products. The same trend of decrease was identified for $20,50 \%$ weight loss and the final residue.

SCF and GO reinforced materials exhibited the same trend as unfilled material. However, the differences in temperatures were less accentuated, which suggests that the composites are more thermally stable than the unfilled UHMWPE. The hybrid composite showed the least variation in thermal stability behavior due to aging, suggesting a synergic effect between the micro and nanofillers. Also, the less considerable changes can be explained by fewer chemical changes in the material due to oxidation, as verified through FTIR (Fig. 6.1.2).

The ND composite showed the opposite behavior compared to the other reinforced and unfilled UHMWPE, as its thermal stability enhanced with hygrothermal aging exposure. One hypothesis for this would be the presence of agglomerates of ND in the material, which was functionalized by the oxidation of the surface, enhancing the thermal behavior of the material. This theory is based on the fact that ND particles are versatile when it comes to functionalization [51], but further investigations are needed to understand the driving mechanism for this behavior. 
Table 6.1.1 Decomposition temperatures obtained from TGA analysis for UHMWPE composites.

\begin{tabular}{ccccccc}
\hline \multirow{2}{*}{ Material } & $\begin{array}{c}\text { Aging } \\
\text { condition }\end{array}$ & $\begin{array}{c}10 \% \mathrm{WL} \\
{\left[{ }^{\circ} \mathrm{C}\right]}\end{array}$ & $\begin{array}{c}20 \% \mathrm{WL} \\
{\left[{ }^{\circ} \mathrm{C}\right]}\end{array}$ & $\begin{array}{c}50 \% \mathrm{WL} \\
{\left[{ }^{\circ} \mathrm{C}\right]}\end{array}$ & $\begin{array}{c}\text { Residue } \\
{\left[{ }^{\circ} \mathrm{C}\right]}\end{array}$ & $\begin{array}{c}\text { Residue } \\
\text { wt\% }\end{array}$ \\
\hline UHMWPE & Before & 460.8 & 469.5 & 481.4 & 511.4 & 3.71 \\
& $\mathrm{RT}$ & 434.5 & 443.7 & 460.8 & 499.7 & 5.38 \\
& $80{ }^{\circ} \mathrm{C}$ & 439.0 & 448.2 & 462.7 & 536.0 & 4.42 \\
& Before & 461.1 & 470.5 & 484.2 & 512.0 & 16.35 \\
SCF & $\mathrm{RT}$ & 453.1 & 464.0 & 478.9 & 504.5 & 17.54 \\
& $80{ }^{\circ} \mathrm{C}$ & 449.9 & 461.1 & 477.6 & 504.5 & 17.01 \\
& Before & 462.8 & 471.8 & 483.9 & 515.2 & 4.904 \\
& $\mathrm{RT}$ & 456.9 & 466.9 & 480.2 & 507.6 & 5.384 \\
& $80{ }^{\circ} \mathrm{C}$ & 454.3 & 463.7 & 477.4 & 508.4 & 6.7 \\
& Before & 437.1 & 448.9 & 468.8 & 501.4 & 6.56 \\
& $\mathrm{RT}$ & 457.5 & 466.3 & 478.9 & 503.2 & 4.328 \\
& $80{ }^{\circ} \mathrm{C}$ & 440.6 & 451.8 & 470.5 & 501.0 & 5.208 \\
& Before & 459.5 & 469.5 & 484.2 & 508.9 & 18.16 \\
& $\mathrm{RT}$ & 453.0 & 464.1 & 480.0 & 506.8 & 18.17 \\
& $80{ }^{\circ} \mathrm{C}$ & 454.1 & 466.1 & 482.0 & 504.5 & 16.85 \\
\hline
\end{tabular}

\subsection{Aging procedure II}

\subsubsection{Water intake}

As previously discussed, when considering water lubricated conditions, it is essential to evaluate the water absorption as the component is directly exposed to the aqueous medium. Absorption of water may affect the mechanical properties, structural integrity, geometry and tribological performance of components. Fig. 6.2.1 presents the results of long-term exposure to water and temperature of the composites.

Samples aged at room temperature exhibited small water intake, with all composites absorbing less than $0.1 \%$ of water in 112 days. This behavior suggests that the presence of reinforcements did not significantly alter the structure of the materials and their water solubility, meaning that UHMWPE polymer matrix drives the water intake. The low intake was expected [20] for the UHMWPE matrix, as the polymer chains are formed by ethylene which is a non-polar structure [74]. Therefore, has low solubility and low affinity to water. The mass of the samples was approximately stable since the $7^{\text {th }}$ exposure day, which means that the samples were saturated. These results suggest, for room temperature, that UHMWPE composites are suitable candidates for waterlubricated conditions, and that GO, ND, and SCF do not significantly affect the water diffusion kinetics of UHMWPE. 


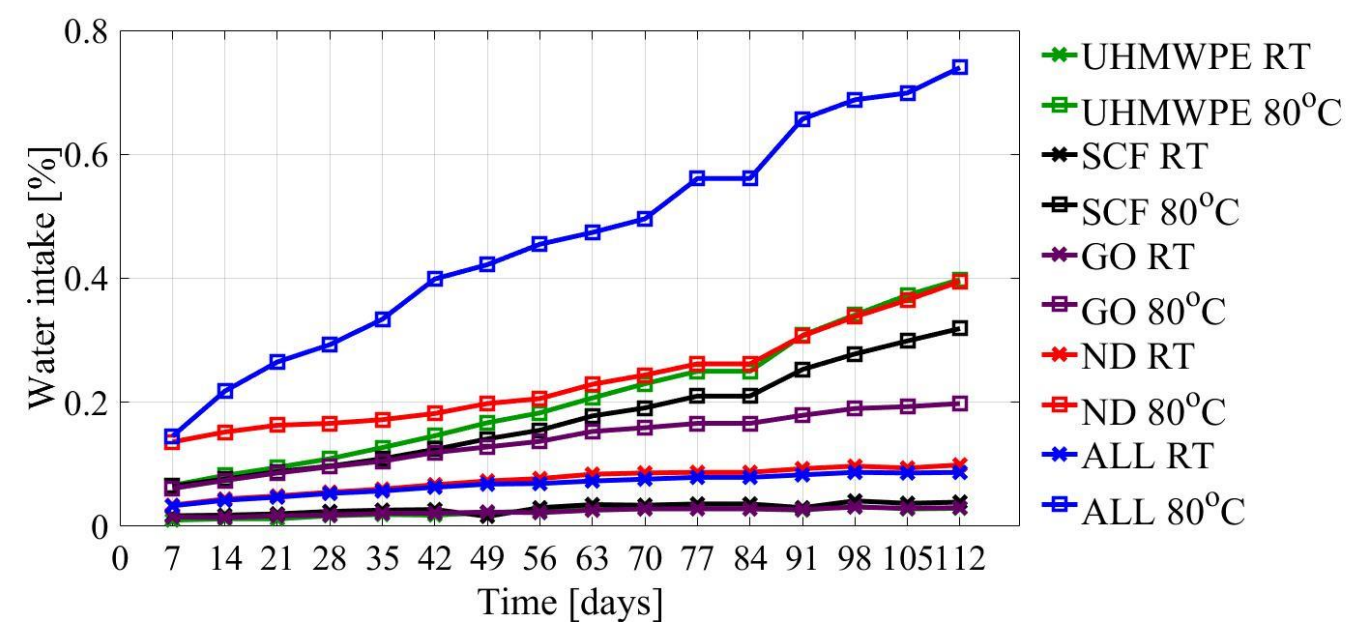

Figure 6.2.1 Water intake for composite materials with long-term exposure to water and temperature.

Elevated temperatures are expected to alter the diffusion kinetics of water into the composites due to the increase in the mobility of molecules, which result in higher diffusion rates. Additionally, increase in temperature could induce defects in the surface such as microcracks, which increase the interfacial area between water and composite, creating preferential diffusion paths. Also, elevated temperatures could cause oxidation, which could result in the scission of monomer chain, modifying the structure of the material, allowing for more absorption [57], [58], [60]. The results presented in the Fig. 6.2.1 followed what was expected, more substantial weight gain if compared to room temperature exposure. Also, the mass did not reach a stable value, which suggests that saturation was not reached, and further mass variation would take place.

Differently, from room temperature, at $80{ }^{\circ} \mathrm{C}$ the composites behave differently regarding absorption. GO reinforced UHMWPE had the lowest mass variation, which can be explained by the addition of a filler that has oxygen (non-polar molecule), meaning that it reduces the affinity with water. The hybrid composite displayed significant more weight variation compared to the other materials. The difference could be explained by the presence of cracks in the surface, which were not identified on the other composites and possibly more excessive oxidation of the surface. The oxidation of the surfaces was verified by FTIR (Fig. 6.2.3 and 6.2.4), which show that all samples started to oxidize. However, there were no significant differences in the severity between the composites, which ruled out the argument that the hybrid composite was exposed to more severe oxidation that the other materials.

\subsubsection{Wettability and SFE}

Wettability is relevant when talking about the tribological performance in lubricated contacts [75]. A material with hydrophobic behavior (contact angle greater than $90^{\circ}$ ), tends to form and maintain a lubricant film. The maintenance of the film occurs due to the low spreading of the lubricant over the surface. On the other hand, a hydrophilic 
material allows the liquid to spread over its surface, meaning that a lubricating film may not form and be maintained.

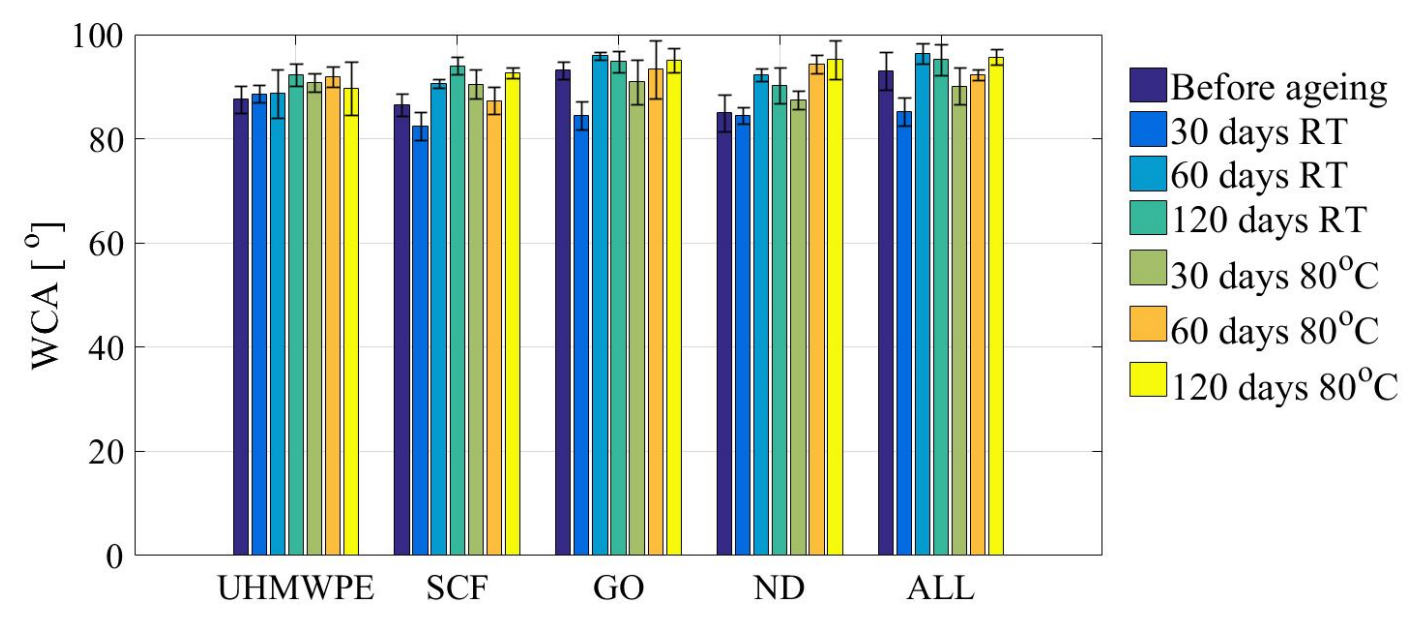

Figure 6.2.2 Water contact angle of the composites with aging time and temperature.

The acquired results for water contact angle are presented in Fig. 6.2.2. The results show that the addition of reinforcements did not significantly change the wettability of the composites, with the WCA being approximately $90^{\circ}$. This value suggests poor spreading of the liquid, which could be translated into proper lubricant film formation and maintenance, and consequently good lubrication. The tendency to form and maintain the lubricant film is confirmed when calculating the SFE of the composites (Table 6.2.1), which showed similar values and predominantly dispersive behavior that results in a hydrophobic surface.

Table 6.2.1 SFE of the composites before aging calculated using OWRK method.

\begin{tabular}{lccc}
\hline Material & SFE $\left[\mathbf{m J . m}{ }^{-2}\right]$ & SFE $^{\text {polar }}\left[\mathbf{m J . m}{ }^{-2}\right]$ & SFE $^{\text {dispersive }}\left[\mathbf{m J . m ^ { - 2 }}\right]$ \\
\hline UHMWPE & $26.65 \pm 0.39$ & $1.83 \pm 0.23$ & $24.81 \pm 0.16$ \\
SCF & $26.59 \pm 0.64$ & $1.10 \pm 0.24$ & $25.49 \pm 0.88$ \\
GO & $33.75 \pm 0.21$ & $0.31 \pm 0.01$ & $33.44 \pm 0.22$ \\
ND & $26.26 \pm 1.50$ & $0.34 \pm 0.36$ & $25.92 \pm 1.85$ \\
GO+ND+SCF & $24.82 \pm 0.16$ & $0.18 \pm 0.01$ & $24.64 \pm 0.16$ \\
\hline
\end{tabular}

As the samples were aged, within the same group of materials, no considerable changes were identified, which suggests that exposure to water and temperature did not affect the SFE. Therefore, it can be implied, for the samples used, that the surface characteristics of the composites are stable even after being hygrothermally aged for 120 days.

\subsubsection{FTIR}

The FTIR results are shown in Fig. 6.2.3 and 6.2.4, where the first figure presents the absorbance of unfilled UHMWPE and the second of the composites. The characteristic peaks are identified as in section 6.1.1. However, small intensity peaks were detected at $1735 \mathrm{~cm}^{-1}$ for samples aged at $80^{\circ} \mathrm{C}$ and 120 days, which corresponds to a $\mathrm{C}=\mathrm{O}$ 
stretching vibration, characteristic of ketones $\left(\mathrm{R}_{2} \mathrm{CO}\right)$ [72], which are products of UHMWPE oxidation [57], [60], [71].

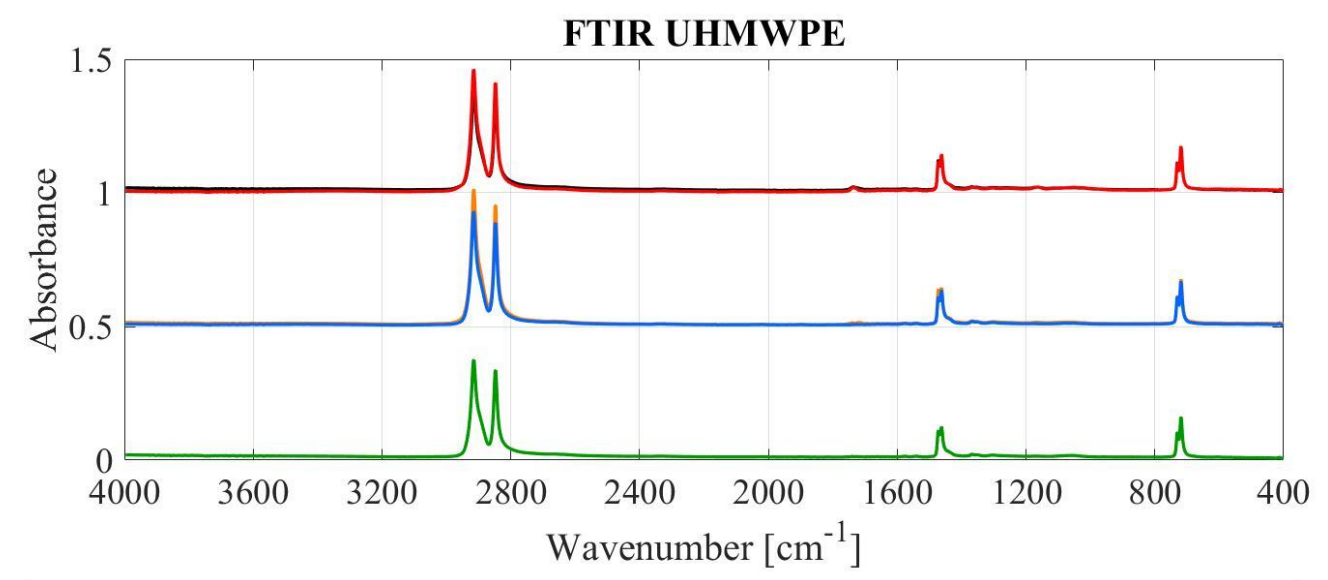

- Before ageing -60 days $\mathrm{RT}-60$ days $80^{\circ} \mathrm{C}-120$ days RT -120 days $80^{\circ} \mathrm{C}$

Figure 6.2.3 ATR-FTIR spectra of UHMWPE.

The composites, as shown in Fig. 6.2.4, followed the same behavior. The characteristic UHMWPE peaks were identified without a shift in the position, and the same $\mathrm{C}=\mathrm{O}$ peak $\left(\sim 1730 \mathrm{~cm}^{-1}\right)$, suggesting that the presence of fillers not affect the oxidation behavior of composites.

a

FTIR UHMWPE+GO

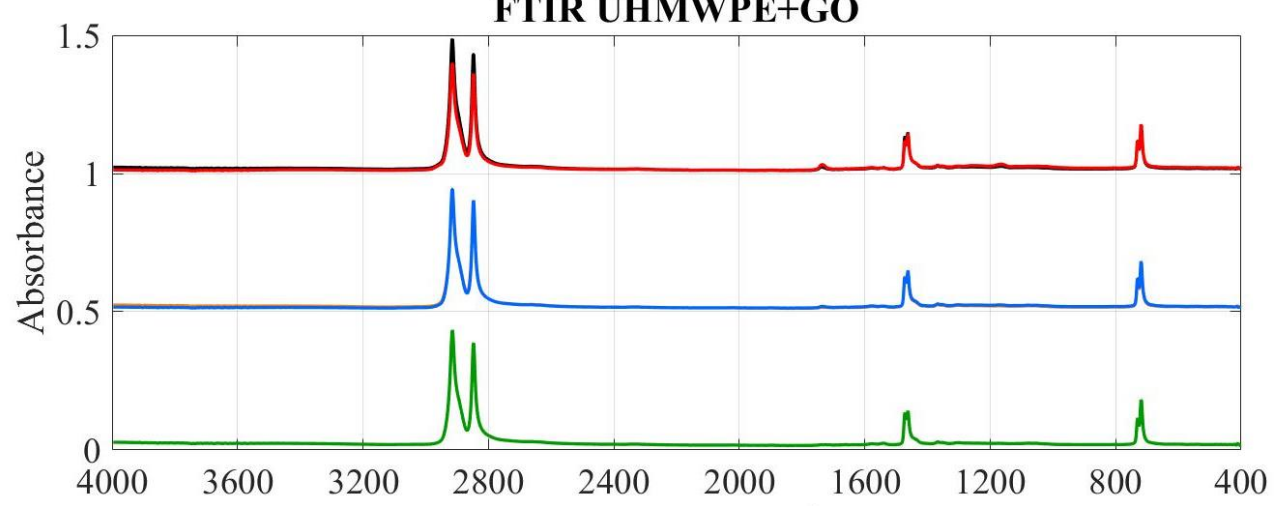

Wavenumber $\left[\mathrm{cm}^{-1}\right]$

- Before ageing -60 days $\mathrm{RT}-60$ days $80^{\circ} \mathrm{C}-120$ days $\mathrm{RT}-120$ days $80^{\circ} \mathrm{C}$

b

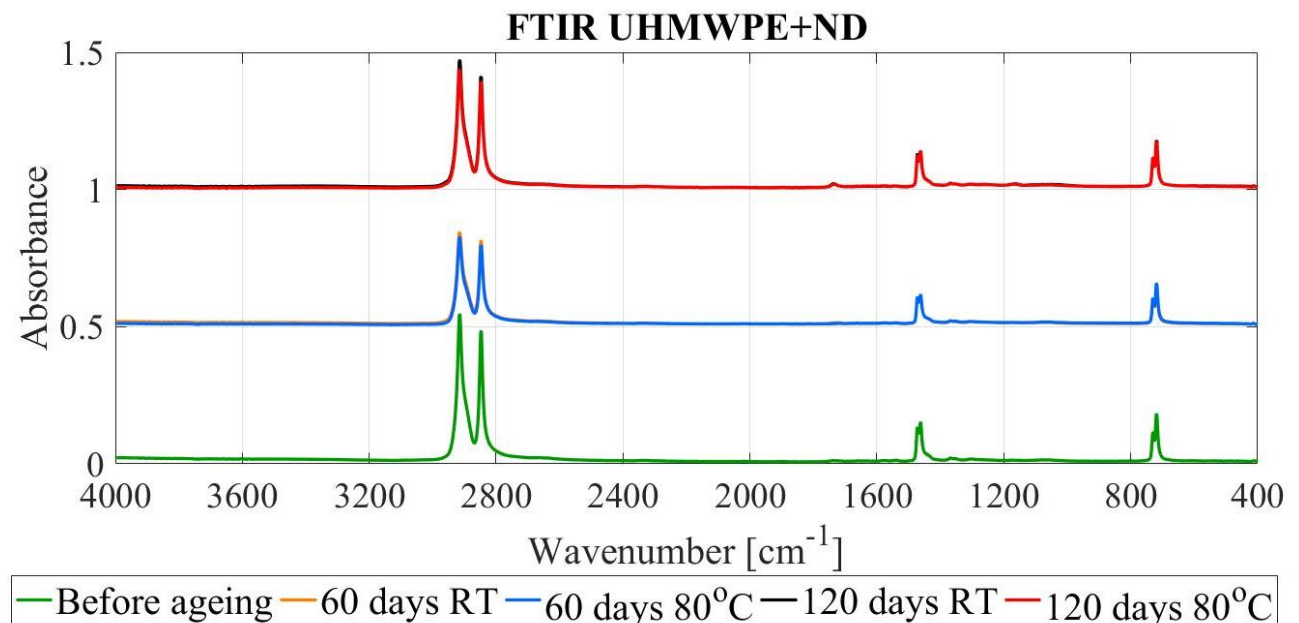




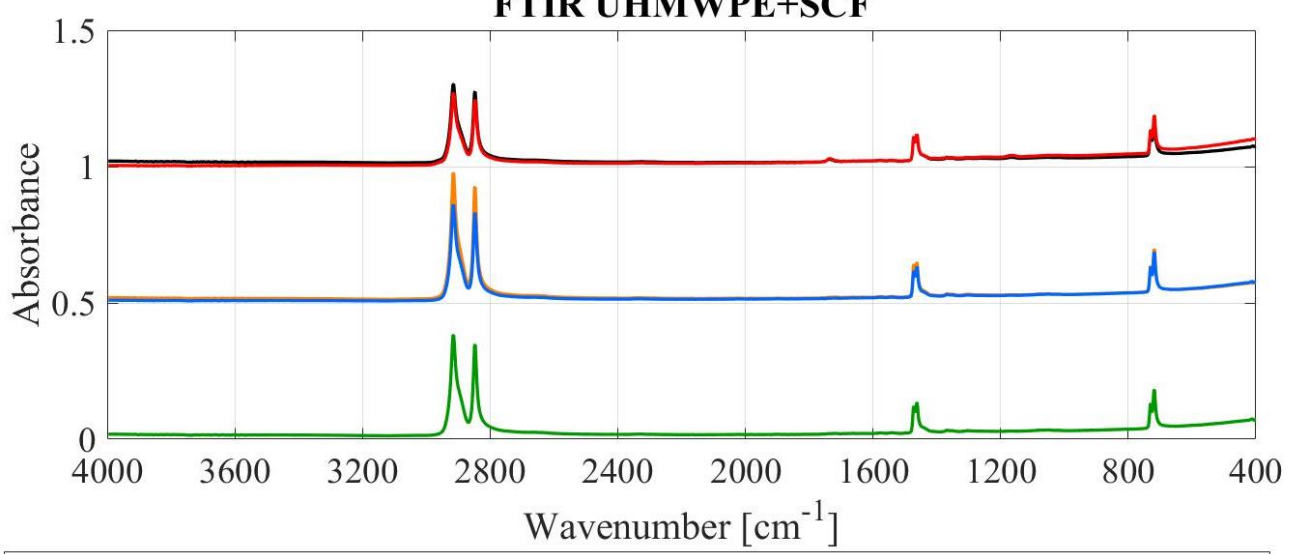

- Before ageing -60 days RT -60 days $80^{\circ} \mathrm{C}-120$ days RT -120 days $80^{\circ} \mathrm{C}$

d

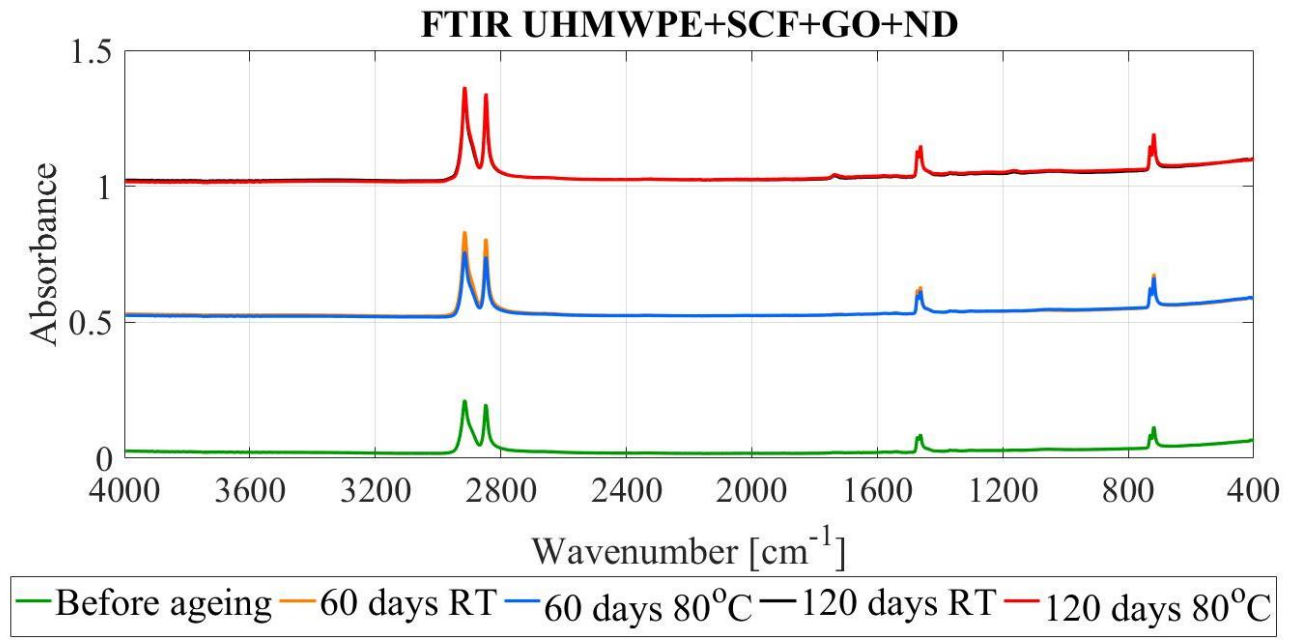

Figure 6.2.4 ATR-FTIR for UHMWPE reinforced with micro and nano-sized fillers. (a) GO, (b) ND, (c) SCF, and (d) hybrid reinforced UHMWPE.

However, it is interesting to compare the results obtained from the aging procedure I (section 6.1.1) and II. Significant differences can be identified in the FTIR spectra, implying that the conditions of the two tests were different. Aging procedure I used smaller sample sizes, less volume of water per sample, a filled smaller container. Whereas aging procedure II used larger samples sizes, more volume of water per sample, half full large container. This differences in the procedure, especially the size of the container could explain the more severe oxidation of samples from procedure I. The smaller volume allowed for quicker pressure build-up, allowing for faster oxidation rates. Thus, the FTIR and TGA results obtained by the two procedures should not be compared, as the test conditions were different.

\subsubsection{DSC}

The degree of crystallinity of material relates to the ratio between crystalline and amorphous phases. Semi-crystalline polymer mechanical properties depend on the crystallinity of the material, as they are dependent on how the polymer structure is distributed and the proportion of organized and random form. Moreover, the mechanical properties affect the tribological behavior, so the varying the crystallinity 
of a polymer may affect the tribological performance, which was identified by Karuppiah et al. when studying the friction and wear of UHMWPE [68].

Changes in the structure may also affect the moisture absorption of the material, where a more substantial content of amorphous phase may allow more absorption due to requiring less energy for the diffusion of water towards the matrix. The addition of reinforcements can increase or decrease the degree of crystallinity of polymers depending on the content and scale of the filler [31]. The calculated crystallinity based on the DSC measurements and equation 3 are presented in table 6.2.2.

Table 6.2.2 Calculated degree of crystallinity of composites.

\begin{tabular}{llllll}
\hline \multicolumn{1}{c}{ Material } & \multicolumn{1}{c}{ Before } & \multicolumn{2}{c}{60 days } & \multicolumn{2}{c}{120 days } \\
& $\mathrm{X}_{\mathrm{c}}[\%]$ & $\mathrm{X}_{\mathrm{c}(\mathrm{RT})}[\%]$ & $\mathrm{X}_{\mathrm{c}\left(80^{\circ} \mathrm{C}\right)}[\%]$ & $\mathrm{X}_{\mathrm{c}(\mathrm{RT})}[\%]$ & $\mathrm{X}_{\mathrm{c}\left(80^{\circ} \mathrm{C}\right)}[\%]$ \\
\hline UHMWPE & 56.17 & 55.26 & 56.66 & 55.93 & 62.57 \\
$\mathrm{SCF}$ & 55.26 & 54.00 & 52.51 & 54.93 & 60.76 \\
$\mathrm{GO}$ & 56.43 & 55.91 & 55.20 & 54.11 & 53.81 \\
$\mathrm{ND}$ & 57.37 & 55.39 & 55.99 & 56.68 & 59.22 \\
GO+ND+SCF & 55.31 & 53.29 & 52.18 & 52.97 & 54.59 \\
\hline
\end{tabular}

Before aging all the materials shown similar degrees of crystallinity, which suggests that reinforcements did not significantly affect the crystallization of the composites. After exposure to both hygrothermal conditions for 60 days, no significant variations in the structure of the polymer were identified. However, when aged for 120 days at elevated temperature, unfilled and SCF reinforced UHMWPE exhibited a slight increase in the degree of crystallinity. This increase could be due to the small degree of oxidation, previously identified by ATR-FTIR analysis (section 6.2.3), that could have caused the crosslinking and scission of the UHMWPE monomer chains [76]. Moreover, oxidation may have induced secondary crystallization at the crystal interfaces and of amorphous regions, increasing the total degree of crystallinity of the materials [58], [60]. The melting temperature of the composites was not affected by the aging exposure and was all around $136{ }^{\circ} \mathrm{C}$. Relating the results of Fig. 6.2.1 and results presented in this section is not trivial, as no direct relation between water absorption and the degree of crystallinity was identified.

\subsubsection{Friction}

The average coefficient of friction for the composites is displayed in Fig. 6.2.5. The values shown are the average friction value for the last 2 hours of the test, which was chosen when considering the steady-state sliding friction.

Comparing the friction behavior of unaged materials, SCF reinforced UHMWPE exhibited the lowest friction coefficient of all the tested materials. The reduction can be attributed to SCFs on the surface partly bearing the load and better heat removal on the contact for the composite material [41]. GO, ND and hybrid reinforced composites also shown a decrease in friction compared to the unfilled, but the effect of the nanoparticles was less pronounced than SCF. 


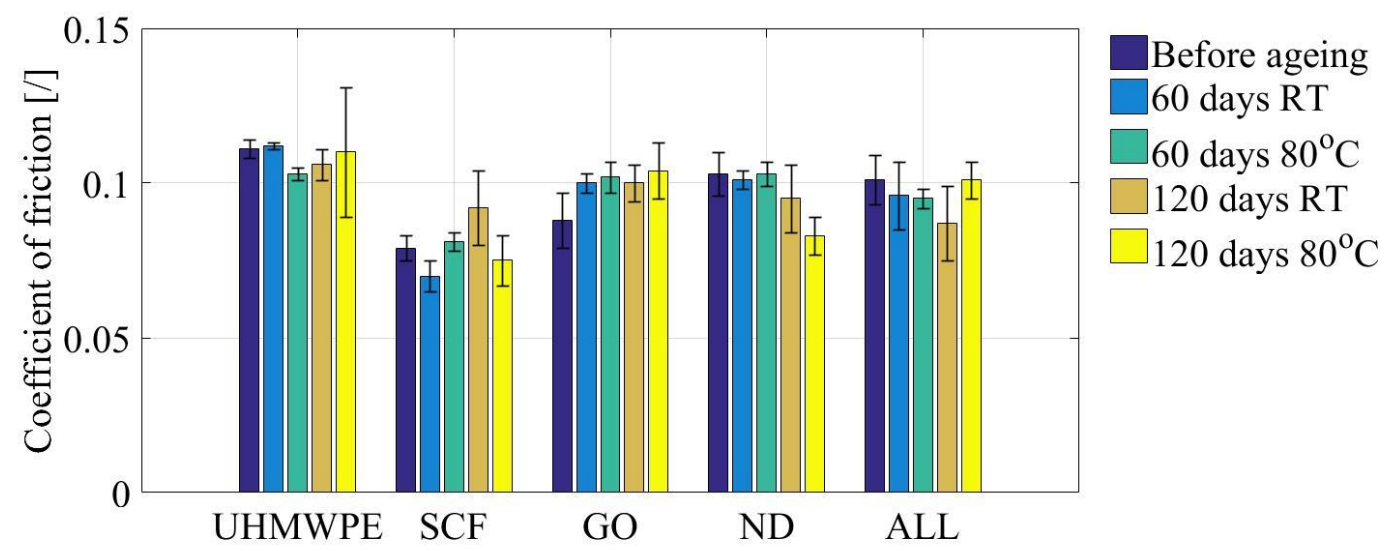

Figure 6.2.5 The coefficient of friction of the composites sliding against Inconel 625 countersurface before and after aging.

Within the same group of materials, no significant differences were identified in the friction behavior of the materials with aging. The constant behavior means that water absorption and slight oxidation of the composites did not have notable effects on the composites for the tested conditions, which suggests that the UHMWPE composites are good candidates for water applications.

As mentioned in section 6.2.2 the tribological behavior is affected by the wettability of the material. Fig 6.2.6 presents the relation between the water contact angle and coefficient of friction of the composites. Analyzing the plot, it is not possible to identify a trend that correlates wettability and friction performance. Therefore, no direct relationship between the two parameters can be implied.

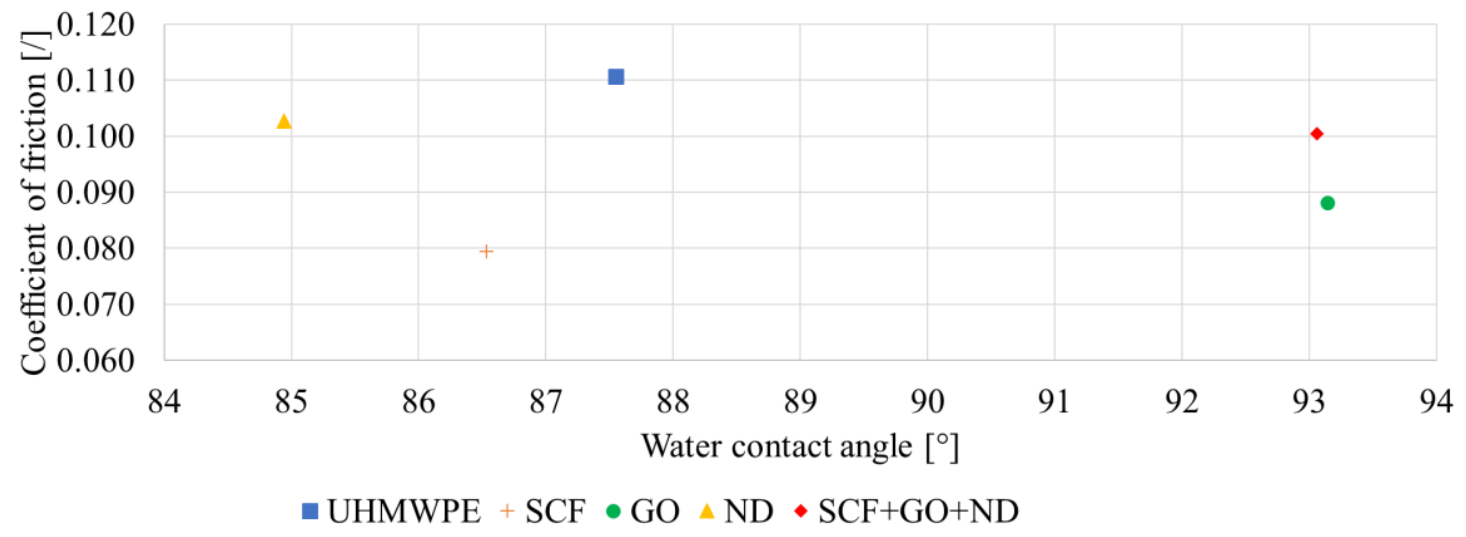

Figure 6.2.6 The relationship between the coefficient of friction and contact angle.

\subsubsection{Wear}

The average specific wear rate of the materials is presented in Fig. 6.2.7. Similar to the coefficient of friction, the SWR was calculated for the last 2 hours of the test to consider the steady-state wear operation (Fig. 5.3.2). 


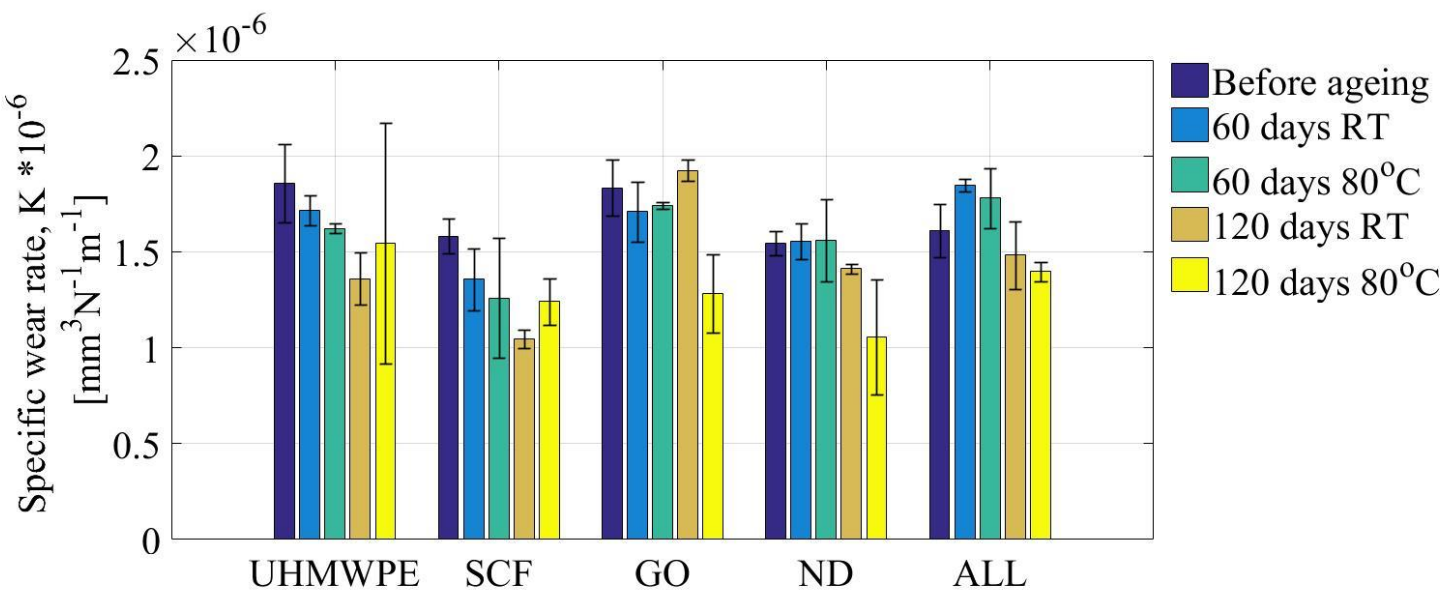

Figure 6.2.7 Specific wear rate of the composites sliding against Inconel 625 countersurface before and after aging.

Comparing the SWR before aging, all the materials exhibited SWR in the same order of magnitude. However, SCF, ND, and hybrid composites showed slightly lower values compared to unfilled and GO reinforced UHMWPE. The lower wear rate of SCF composite is attributed to the partial bearing of the load by the fibers, which reduces the contact between the UHMWPE matrix and the countersurface while protecting the polymer from abrasion [41]. ND particles reduce wear because of their innate superior hardness, which prevents or reduce asperity to asperity contact between the two surfaces [48], [53]. Hybrid composites did not exhibit a synergic effect between micro and nanofillers, which was identified in previous work [31].

Within the same group of materials, it is possible to identify that hygrothermal aging did not considerably alter the wear performance of the materials. Similar to the friction behavior, this means that the water absorption and oxidation did not considerably modify the tribological performance of the composites. Fig. 6.2.8 shows the relationship between the coefficient of friction and SWR of the composites. The figure helps to illustrate the tribological stability of the materials regarding aging.

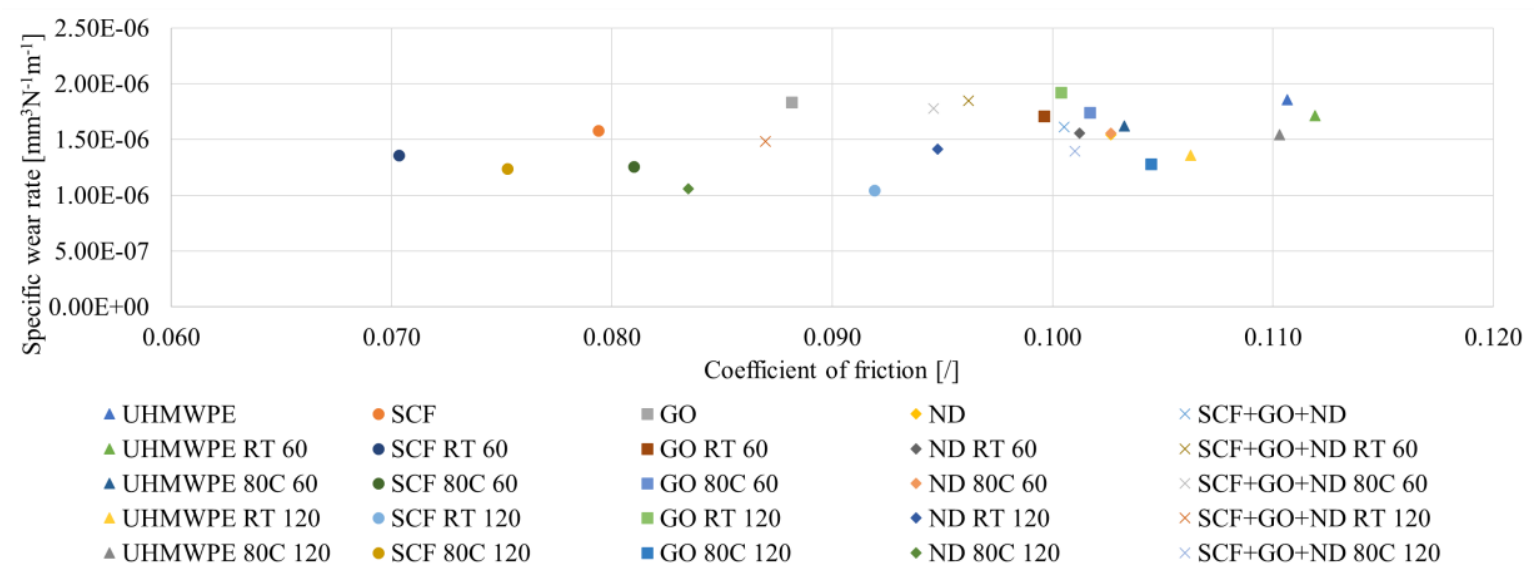

Figure 6.2.8 The relationship between SWR and coefficient of friction.

Fig. 6.2.9 presents the relationship between SWR and water contact angle. Similarly to the coefficient of friction, no trends correlating SWR and wettability were identified. Thus, no direct relationship between the two could be drawn. 


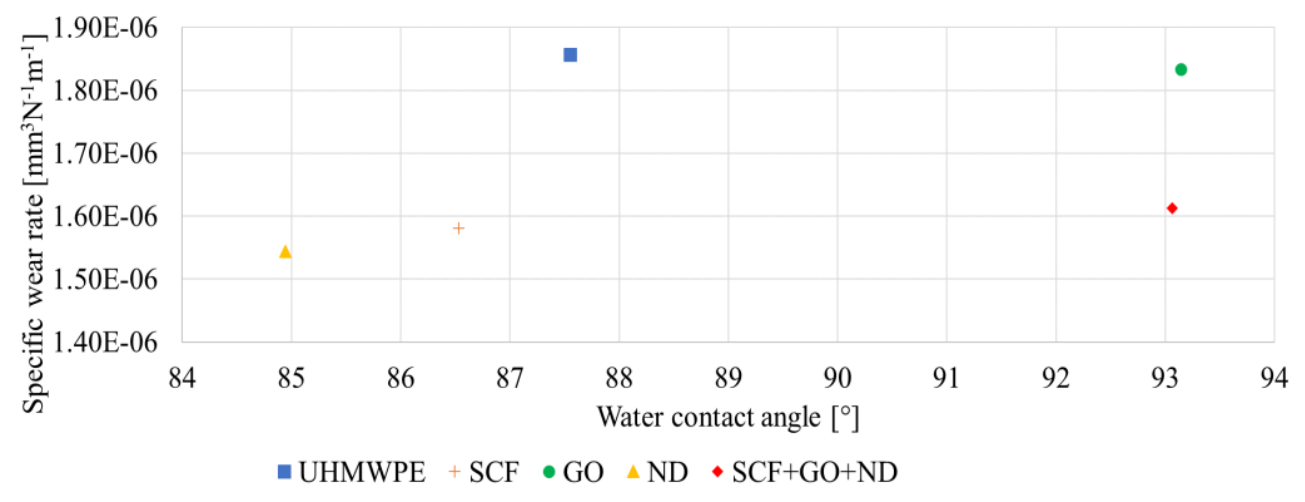

Figure 6.2.9 The relationship between SWR and contact angle.

As discussed previously, one of the limitations of UHMWPE is the susceptibility to high abrasive wear. For that reason, studying the wear mechanism of the composites is relevant. In Fig. 6.2.10, the pin surfaces of unfilled UHMWPE are shown for before aging, and 120 days aged conditions.

The images show information about the wear mechanism of the composites. Grooves with plastic deformation on wedges are identified on the pin surfaces, which are predominant in abrasive wear conditions. Furthermore, no differences in the removal mechanism were identified for samples aged at room and elevated temperatures. Addition of reinforcements affected the wear, but no changes in the wear mechanism were identified as seen in Fig. 6.2.11. Therefore, it is possible to conclude that hygrothermal aging and presence of reinforcements, for the tested conditions, did not affect the mechanism of material removal of the composites.

The Inconel 625 countersurfaces were also analyzed to study the wear tracks and formation of the transfer film. As previously cited, the UHMWPE self-lubricating mechanism is the formation of a passive film that is transferred to the mating surface reducing friction and wear between them. Fig. 6.2.12 shows the wear track of unaged hybrid UHMWPE - Inconel contact.

The material transfer was identified on the metallic surface, but no continuous film was formed. The non-continuity of the film can be attributed to different reasons, one being lubricated conditions. Previous works showed that presence of lubricant may hinder the formation of transfer film due to a reduction in the severity of polymer/metal contact, and may wash out the spalled film [25], [77].

The countersurface roughness is also essential for the formation and maintenance of the transfer film [78]. Therefore, another reason for discontinuous transfer film would be hydrodynamic effects resulted from the initially chosen topography, and the smoothening of the surface caused by the sliding motion. 

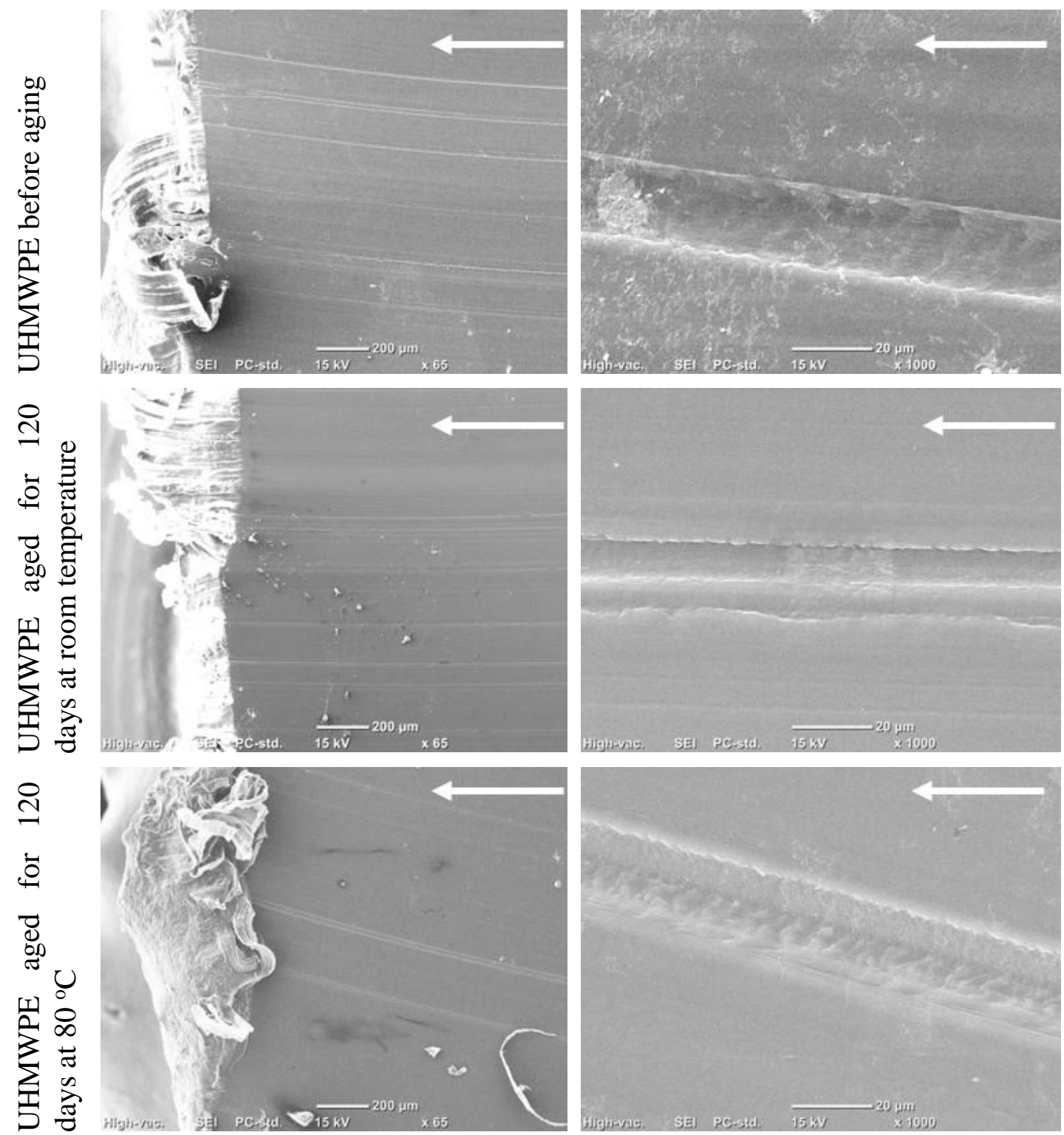

Figure 6.2.10 Worn pin surface of unfilled UHMWPE for different test aging conditions. (Left) Magnification 65x. (Right) Magnification 1000x and sliding direction indicated by the arrow. 

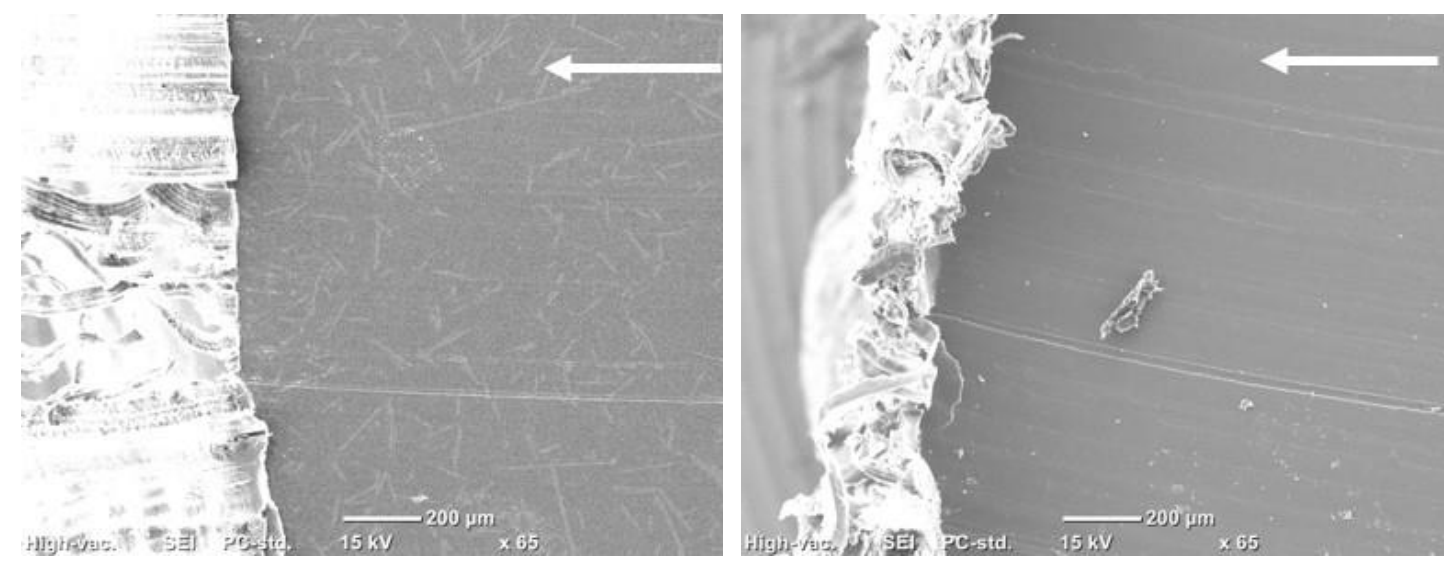

Figure 6.2.11(Left) SCF reinforced UHMWPE unaged worn pin surface. (Right) GO reinforced UHMWPE unaged worn pin surface.

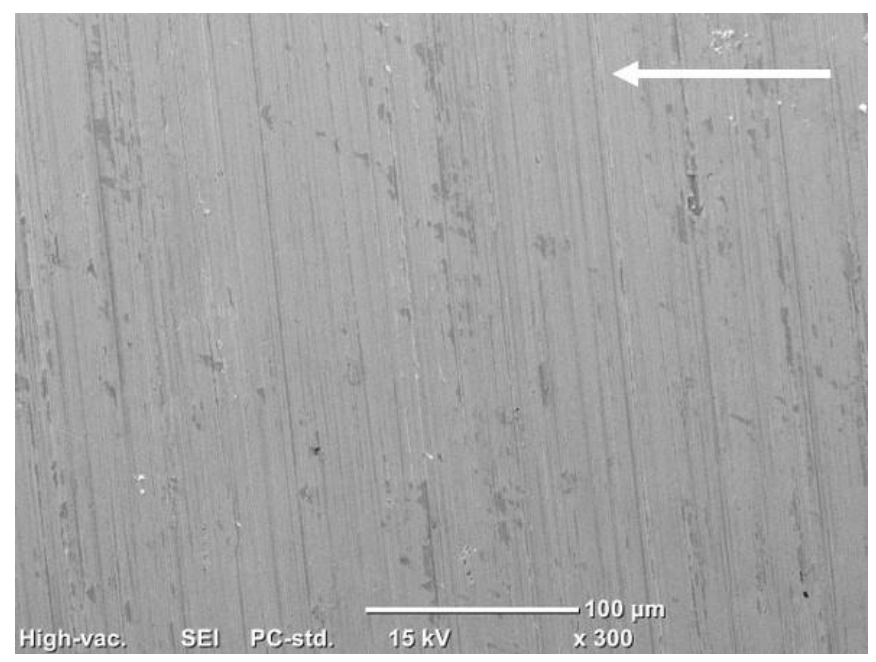

Figure 6.2.12 Wear track of hybrid UHMWPE/metal contact.

\section{Conclusions}

This study focused on the effect of hygrothermal aging on the tribological performance of carbon-reinforced UHMWPE composites in water-lubricated conditions. The work was a continuation of [61], where the composition of the composites was chosen based on the best performance in the previous study. The effect of water and temperature exposure was investigated regarding water absorption, the degree of crystallinity, thermal stability, friction, and wear. The conclusions drawn are listed below.

- Thermal stability of the composites was affected due to oxidation of the material during hygrothermal aging;

- UHMWPE composites displayed low water absorption for room temperature aging. Addition of reinforcements did not significantly alter the absorption kinetics;

- Samples aged at elevated temperatures exhibited higher water intake than room temperature, which can be increased mobility of molecules and oxidation of the samples due to higher temperatures; 
- Wettability of the samples was not considerably affected by aging. Samples presented close to $90^{\circ}$ contact before and after aging, which consists of hydrophobic behavior;

- Unfilled and SCF reinforced UHMWPE displayed an increase in crystallinity when aged at $80{ }^{\circ} \mathrm{C}$ for 120 days. The increase may have happened due to scission of the polymer chains, and secondary crystallization induced by higher temperature exposure;

- UHMWPE composites friction and wear were not significantly affected by hygrothermal aging, which suggests that these materials are good candidates for water-lubricated applications in which temperatures up to $80^{\circ} \mathrm{C}$.

\section{Future work}

Considering the state of polymer composites research in tribology and the current activities of TRIBOLAB at LTU, work in the following areas is suggested:

- Further investigate the effect of ND on the mechanical, thermal and tribological performance of UHMWPE;

- Study of the tribological performance of UHMWPE composites in saline waterlubricated conditions;

- Comparison of the tribological performance of UHMWPE composites in environmentally accepted lubricants (EALs) and water-lubricated contacts;

- Investigate the influence of the contact pressure on the tribological performance of hybrid UHMWPE composites;

- Investigate the tribological performance of other UHMWPE composites in dry and water-lubricated conditions. Examples of composites could be UHMWPE+PTFE+SCF and UHMWPE+PTFE+ND.

\section{References}

[1] G. W. Stachowiak and A. W. Batchelor, Engineering tribology. 2013.

[2] R. (Ramsey) Gohar, Elastohydrodynamics. Imperial College Press, 2001.

[3] W. V. Smith, "Material selection criteria for water lubrication," Wear, vol. 25, no. 2, pp. 139-153, 1973.

[4] B. M. Ginzburg, D. G. Tochil'nikov, V. E. Bakhareva, A. V. Anisimov, and O. F. Kireenko, "Polymeric materials for water-lubricated plain bearings," Russ. J. Appl. Chem., vol. 79, no. 5, pp. 695-706, 2006.

[5] G. Kreysa and M. Schütze, Eds., Corrosion Handbook. Weinheim, Germany: Wiley-VCH Verlag GmbH \& Co. KGaA, 2008.

[6] M. C. Andrew W. Batchelor, Service Characteristics of Biomedical Materials and Implants. Imperial College Press, 2004.

[7] R. A. Buchanan, E. D. Rigney, and J. M. Williams, "Ion implantation of surgical Ti-6Al-4V for improved resistance to wear-accelerated corrosion," J. Biomed. Mater. Res., vol. 21, no. 3, pp. 355-366, Mar. 1987.

[8] J. Wang, F. Yan, and Q. Xue, "Tribological behaviors of some polymeric materials in sea water," Sci. Bull., vol. 54, no. 24, pp. 4541-4548, 2009. 
[9] A. Golchin, "Polymeric Materials for Bearing Applications," Lulea Technical University, 2015.

[10] J. K. Lancaster, "Lubrication of carbon fibre-reinforced polymers part I-Water and aqueous solutions," Wear, vol. 20, no. 3, pp. 315-333, Jul. 1972.

[11] A. Ashori and S. Sheshmani, "Hybrid composites made from recycled materials: Moisture absorption and thickness swelling behavior," Bioresour. Technol., vol. 101, no. 12, pp. 4717-4720, Jun. 2010.

[12] H.-S. Yang, H.-J. Kim, H.-J. Park, B.-J. Lee, and T.-S. Hwang, "Water absorption behavior and mechanical properties of lignocellulosic fillerpolyolefin bio-composites," Compos. Struct., vol. 72, no. 4, pp. 429-437, Apr. 2006.

[13] B. Mohebby, H. Younesi, A. Ghotbifar, and S. Kazemi-Najafi, "Water and moisture absorption and thickness swelling behavior in polypropylene/wood flour/glass fiber hybrid composites," J. Reinf. Plast. Compos., vol. 29, no. 6, pp. 830-839, 2010.

[14] N. I. Zifeng and C. Guomei, "Wettability and Water Absorption of Irradiation Cross-linked UHMWPE," vol. 290, pp. 1402-1405, 2011.

[15] E. Rabinowicz, Friction and Wear of Materials. Wiley, 1995, 1995.

[16] D. Jalali-Vahid, M. Jagatia, Z. M. Jin, and D. Dowson, "Prediction of lubricating film thickness in UHMWPE hip joint replacements," J. Biomech., vol. 34, no. 2, pp. 261-266, Feb. 2001.

[17] S. Béland, "6 - Joining Thermoplastic Composites," in High Performance Thermoplastic Resins and their Composites, 1990, pp. 125-135.

[18] P. H. Pinchbeck, “A Review of Plastic Materials,” Wear, vol. 5, no. 12, pp. 85$113,1961$.

[19] H. Becker and C. Gärtner, "Polymer microfabrication technologies for microfluidic systems," 2007.

[20] S. M. Kurtz, UHMWPE biomaterials handbook: ultra high molecular weight polyethylene in total joint replacement and medical devices. Elsevier/Academic Press, 2009.

[21] N. S. Muralisrinivasan, The basics of troubleshooting in plastics processing : an introductory practical guide. Scrivener, 2011.

[22] M. M. Renfrew and E. E. Lewis, "Polytetrafluoroethylene. Heat Resistant, Chemically Inert Plastic," Ind. Eng. Chem., vol. 38, no. 9, pp. 870-877, 1946.

[23] A. Golchin, G. F. Simmons, S. B. Glavatskih, and B. Prakash, "Tribological behaviour of polymeric materials in water-lubricated contacts," Proc. Inst. Mech. Eng. Part J-Journal Eng. Tribol., vol. 227, no. 8, pp. 811-825, 2013.

[24] J. Sukumaran, J. De Pauw, P. D. Neis, L. F. Tóth, and P. De Baets, "Revisiting polymer tribology for heavy duty application," Wear, vol. 376-377, pp. 13211332, 2017.

[25] K. Marcus and C. Allen, "The Sliding Wear of Ultrahigh Molecular-Weight Polyethylene in an Aqueous Environment," Wear, vol. 178, no. 1-2, pp. 17-28, 1994. 
[26] K. Friedrich, Z. Zhang, and A. K. Schlarb, "Effects of various fillers on the sliding wear of polymer composites," Compos. Sci. Technol., vol. 65, no. 15-16 SPEC. ISS., pp. 2329-2343, 2005.

[27] Y. S. Zoo, J. W. An, D. P. Lim, and D. S. Lim, "Effect of carbon nanotube addtiion on tribological behavior of UHMWPE," Tribol. Lett., vol. 16, no. 4, p. 305, 2004.

[28] Z. Tai, Y. Chen, Y. An, X. Yan, and Q. Xue, "Tribological behavior of UHMWPE reinforced with graphene oxide nanosheets," Tribol. Lett., vol. 46, no. 1, pp. 55-63, 2012.

[29] S. Zhou, Q. Zhang, C. Wu, and J. Huang, "Effect of carbon fiber reinforcement on the mechanical and tribological properties of polyamide6/polyphenylene sulfide composites," Mater. Des., vol. 44, pp. 493-499, 2013.

[30] J. P. Davim and R. Cardoso, "Effect of the reinforcement (carbon or glass fibres) on friction and wear behaviour of the PEEK against steel surface at long dry sliding," Wear, vol. 266, no. 7-8, pp. 795-799, 2009.

[31] H. S. Vadivel, A. Golchin, and N. Emami, "Tribological behaviour of carbon filled hybrid UHMWPE composites in water," Tribol. Int., vol. 124, no. October 2017, pp. 169-177, 2018.

[32] S. Suñer, R. Joffe, J. L. Tipper, and N. Emami, "Ultra high molecular weight polyethylene/graphene oxide nanocomposites: Thermal, mechanical and wettability characterisation," Compos. Part B Eng., vol. 78, pp. 185-191, 2015.

[33] A. Golchin, A. Wikner, and N. Emami, "An investigation into tribological behaviour of multi-walled carbon nanotube/graphene oxide reinforced UHMWPE in water lubricated contacts," Tribol. Int., vol. 95, pp. 156-161, 2016.

[34] A. Golchin, A. Villain, and N. Emami, "Tribological behaviour of nanodiamond reinforced UHMWPE in water-lubricated contacts," Tribol. Int., vol. 110, pp. 195-200, 2017.

[35] E. Fitzer, "Pan-based carbon fibers-present state and trend of the technology from the viewpoint of possibilities and limits to influence and to control the fiber properties by the process parameters," Carbon N. Y., vol. 27, no. 5, pp. 621-645, 1989.

[36] X. Huang, "Fabrication and properties of carbon fibers," Materials (Basel)., vol. 2, no. 4, pp. 2369-2403, 2009.

[37] T. Roberts, "The Carbon Fiber Industry: Global Strategic Market Evaluation 2006-2010," 2006.

[38] W. D. Callister, Fundamentals of materials science and engineering: an integrated approach. John Wiley \& Sons, 2005.

[39] D. D. L. Chung, Carbon fiber composites. Butterworth-Heinemann, 1994.

[40] E. G. Wolff, "Stiffness-Thermal Expansion Relationships in High Modulus Carbon Fibers," J. Compos. Mater., vol. 21, no. 1, pp. 81-97, Jan. 1987.

[41] D. I. Chukov et al., "Investigation of structure, mechanical and tribological properties of short carbon fiber reinforced UHMWPE-matrix composites," Compos. Part B Eng., vol. 76, pp. 79-88, 2015. 
[42] A. A. El-Sayed, M. G. El-Sherbiny, A. S. Abo-El-Ezz, and G. A. Aggag, "Friction and wear properties of polymeric composite materials for bearing applications," Wear, vol. 184, no. 1, pp. 45-53, Apr. 1995.

[43] X. Dangsheng, "Friction and wear properties of UHMWPE composites reinforced with carbon fiber," Mater. Lett., vol. 59, no. 2-3, pp. 175-179, 2005.

[44] D. R. Dreyer, S. Park, C. W. Bielawski, and R. S. Ruoff, "The chemistry of graphene oxide," Chem. Soc. Rev., vol. 39, pp. 228-240, 2010.

[45] F. Perrozzi, S. Prezioso, and L. Ottaviano, "Graphene oxide: From fundamentals to applications," J. Phys. Condens. Matter, vol. 27, no. 1, p. 13002, 2015.

[46] Y. Zhu et al., "Graphene and graphene oxide: Synthesis, properties, and applications," Adv. Mater., vol. 22, no. 35, pp. 3906-3924, 2010.

[47] L. YuHong, W. XiaoKang, P. GuoShun, and L. JianBin, "A comparative study between graphene oxide and diamond nanoparticles as water-based lubricating additives," Sci China Tech Sci, vol. 56, no. 56, pp. 152-157, 2013.

[48] V. N. Mochalin, O. Shenderova, D. Ho, and Y. Gogotsi, "The properties and applications of nanodiamonds," Nat. Nanotechnol., vol. 7, no. 1, pp. 11-23, 2012.

[49] A. Aleksenskiy, M. Baidakova, V. Osipov, and A. Vul', "The Fundamental Properties and Characteristics of Nanodiamonds," in Nanodiamonds, Boston, MA: Springer US, 2010, pp. 55-77.

[50] D. R. Askeland, The Science and Engineering of Materials. Boston, MA: Springer US, 1996.

[51] T. Meinhardt, D. Lang, H. Dill, and A. Krueger, "Pushing the Functionality of Diamond Nanoparticles to New Horizons: Orthogonally Functionalized Nanodiamond Using Click Chemistry," Adv. Funct. Mater., vol. 21, no. 3, pp. 494-500, Feb. 2011.

[52] O. Shenderova et al., "Surface chemistry and properties of ozone-purified detonation nanodiamonds," J. Phys. Chem. C, vol. 115, no. 20, pp. 9827-9837, 2011.

[53] M. G. Ivanov, S. V. Pavlyshko, D. M. Ivanov, I. Petrov, and O. Shenderova, "Synergistic Compositions of Colloidal Nanodiamond as Lubricant-additive," J. Vac. Sci. Technol. B, Nanotechnol. Microelectron. Mater. Process. Meas. Phenom., vol. 28, no. 4, pp. 869-877, 2010.

[54] C. C. Chou and S. H. Lee, "Tribological behavior of nanodiamond-dispersed lubricants on carbon steels and aluminum alloy," Wear, vol. 269, no. 11-12, pp. 757-762, 2010.

[55] L. Costa, P. Bracco, E. Brach Del Prever, M. P. Luda, and L. Trossarelli, "Analysis of products diffused into UHMWPE prosthetic components in vivo," Biomaterials, vol. 22, no. 4, pp. 307-315, 2001.

[56] R. S. Benson, "Use of radiation in biomaterials science," Nucl. Instruments Methods Phys. Res. Sect. B Beam Interact. with Mater. Atoms, vol. 191, no. 14, pp. 752-757, 2002.

[57] F. J. Medel, F. García-Álvarez, E. Gómez-Barrena, and J. A. Puértolas, 
"Microstructure changes of extruded ultra high molecular weight polyethylene after gamma irradiation and shelf-aging," Polym. Degrad. Stab., vol. 88, no. 3, pp. 435-443, 2005.

[58] F. J. Buchanan, J. R. White, B. Sim, and S. Downes, "The influence of gamma irradiation and aging on degradation mechanisms of ultra-high molecular weight polyethylene," J. Mater. Sci. Mater. Med., vol. 12, no. 1, pp. 29-37, 2001.

[59] J. Dawson, "The Effects of Gamma Radiation Sterilisation on Ultra High Molecular Weight Polyethylene," in Ageing Studies and Lifetime Extension of Materials, Boston, MA: Springer US, 2001, pp. 155-160.

[60] F. J. Medel, C. M. Rimnac, and S. M. Kurtz, "On the assessment of oxidative and microstructural changes after in vivo degradation of historical UHMWPE knee components by means of vibrational spectroscopies and nanoindentation," J. Biomed. Mater. Res. - Part A, vol. 89, no. 2, pp. 530-538, 2009.

[61] H. S. Vadivel, "Tribological Behaviour of Hybrid Carbon Filled UHMWPE Composites in Water," Lulea University of technology, 2016.

[62] V. Shankar, K. Bhanu Sankara Rao, and S. . Mannan, "Microstructure and mechanical properties of Inconel 625 superalloy," J. Nucl. Mater., vol. 288, no. 2, pp. 222-232, 2001.

[63] ASTM B446-03, "Standard Specification for Nickel-Chromium-MolybdenumColumbium Alloy ( UNS N06625 ), Nickel-Chromium-Molybdenum-Silicon Alloy ( UNS N06219 ), and Nickel-Chromium-Molybdenum-Tungsten Alloy (UNS N06650) Rod and Bar," ASTM Int., no. Reapproved 2014, pp. 1-7, 2014.

[64] F. H. Mohamed, A.-H. I. Mourad, and D. C. Barton, "UV irradiation and aging effects on nanoscale mechanical properties of ultra high molecular weight polyethylene for biomedical implants," Plast. Rubber Compos., vol. 37, no. 8, pp. 346-352, Oct. 2008.

[65] S. Jana and W. H. Zhong, "Effects of Hygrothermal Conditions and UV Radiation on UHMWPE Fibers/Nanofiber-Epoxy Composites," J. Compos. Mater., vol. 41, no. 24, pp. 2897-2914, Dec. 2007.

[66] D. K. Owens and R. C. Wendt, "Estimation of the surface free energy of polymers," J. Appl. Polym. Sci., vol. 13, no. 8, pp. 1741-1747, Aug. 1969.

[67] B. (Barbara H. . Stuart, Infrared spectroscopy: fundamentals and applications. J. Wiley, 2004.

[68] K. S. Kanaga Karuppiah et al., "Friction and wear behavior of ultra-high molecular weight polyethylene as a function of polymer crystallinity," Acta Biomater., vol. 4, no. 5, pp. 1401-1410, 2008.

[69] M. R. Kessler, Advanced Topics in Characterization of Composites. Trafford Publishing, 2004.

[70] R. Kumar, B. Prakash, and A. Sethuramiah, "A systematic methodology to characterise the running-in and steady-state wear processes," Wear, vol. 252, pp. 445-453, 2002.

[71] I. Bykova et al., "Physical properties and biocompatibility of UHMWPE-derived materials modified by synchrotron radiation," J. Mater. Sci. Mater. Med., vol. 25, no. 8, pp. 1843-1852, 2014. 
[72] G. Gauglitz and T. Vo-Dinh, Eds., Handbook of Spectroscopy. Weinheim, FRG: Wiley-VCH Verlag GmbH \& Co. KGaA, 2003.

[73] L. Zhang, Y. Sawae, T. Yamaguchi, T. Murakami, and H. Yang, "Effect of radiation dose on depth-dependent oxidation and wear of shelf-aged gammairradiated ultra-high molecular weight polyethylene (UHMWPE)," Tribol. Int., vol. 89, pp. 78-85, 2015.

[74] J. Clayden, Organic Chemistry. Oxford University Press, 2001.

[75] A. Borruto, G. Crivellone, and F. Marani, "Influence of surface wettability on friction and wear tests," Wear, vol. 222, no. 1, pp. 57-65, 1998.

[76] M. Goldman, R. Gronsky, and L. Pruitt, "The influence of sterilization technique and ageing on the structure and morphology of medical-grade ultrahigh molecular weight polyethylene," J. Mater. Sci. Mater. Med., vol. 9, no. 4, pp. 207-212, 1998.

[77] O. Jacobs, R. Jaskulka, C. Yan, and W. Wu, "On the effect of counterface material and aqueous environment on the sliding wear of various PEEK compounds," Tribol. Lett., vol. 18, no. 3, pp. 359-372, Mar. 2005.

[78] J. R. Cooper, D. Dowson, and J. Fisher, "The Effect of Transfer Film and Surface Roughness on the Wear of Lubricated Ultra-High Molecular Weight Polyethylene," Clin. Mater., vol. 14, pp. 295-302, 1993. 